\title{
Measuring Income and Wealth at the Top Using Administrative and Survey Data
}

\begin{abstract}
Most available estimates of U.S. wealth and income concentration indicate that the top shares are high and have been rising in recent decades, but there is some disagreement about specific levels and trends. Household surveys are the traditional data source used to measure the top shares, but recent studies using administrative tax records suggest that these survey-based top share estimates may not be capturing all of the increasing concentration. In this paper, we reconcile the divergent top share estimates, showing how the choices of data sets and methodological decisions affect levels and trends. Relative to the new and most widely cited top share estimates based on administrative tax data alone, our preferred estimates for both wealth and income concentration are lower and have been rising less rapidly in recent years.
\end{abstract}

nderstanding the determinants and effects of wealth and income inequality are mainstays of political economy. Within the general topic of inequality, the study of the top wealth and income shares garners particular interest. Measuring and explaining wealth and income concentration has challenged economists at least since Vilfredo Pareto (1896) and Simon Kuznets (1953), and the high-quality, micro-level administrative tax data that have recently been made available are generating renewed interest in the shares of resources controlled by the top wealth and income groups. Indeed, the striking trends in top U.S. wealth and income shares reported in the most widely cited studies based on these newly available administrative data sets are now accepted as facts to be embraced and potentially addressed by policymakers. These observations about levels

1. This paper was written while Jacob Krimmel was a research assistant at the Federal Reserve Board. 
and trends in top wealth and income shares have begun to transcend academic debates, entering the mainstream political arena through best sellers such as those by Raghuram Rajan (2010), Joseph Stiglitz (2012), and Thomas Piketty (2014), and through political movements such as Occupy Wall Street.

Despite the political controversies generated by the estimated top wealth and income shares, relatively little attention has been paid to these estimates' sensitivity to data and methodology. ${ }^{2}$ For example, using administrative income tax data, Emmanuel Saez and Gabriel Zucman (2016) estimate that the top 1 percent (by wealth) had a wealth share of 42 percent in 2013, up from 29 percent in 1992. However, the Survey of Consumer Finances (SCF), which combines administrative and survey data, shows less than half the increase in the top 1 percent's wealth share, rising from 30 percent in 1992 to 36 percent in 2013 (figure 1). Similarly, Piketty and Saez $(2003)^{4}$ show that the top 1 percent (by income) had a 23 percent income share in 2012, an increase of 10 percentage points since 1992. The SCF shows a 20 percent income share for the top 1 percent in 2012, an increase of 8 percentage points since 1991 (figure 2). ${ }^{5}$ Differences in levels and trends in the top wealth and income shares at higher fractiles, such as the top 0.1 percent, are even more striking. ${ }^{6}$

The goals of this paper are to investigate why the various types of data and approaches are giving different answers about top wealth and income shares, and to provide preferred estimates that reflect what can best be gleaned from all the available data, including macro data. The two main sources of micro data used here are administrative tax records and the SCF household survey. These data sources rely on different wealth and income concepts as well as different measurements of wealth and income. In this

2. Notable exceptions include, for the top income shares, Congressional Budget Office (2014); Burkhauser, Larrimore, and Simon (2012); Burkhauser and others (2012); and Smeeding and Thompson (2011). For the top wealth shares, notable exceptions include Kopczuk (2015b).

3. Bricker and others (2014) describe the results from the latest SCF, conducted in 2013. A slow rise in the top wealth shares is also consistent with estimates derived from administrative estate tax data (Kopczuk and Saez 2004).

4. Piketty and Saez regularly update the tables and statistics from their 2003 paper. The most recent version, updated to 2014, is available at http://eml.berkeley.edu/ saez/ TabFig2014prel.xls. We refer to these updated data throughout this paper.

5. SCF income values are for the year preceding the survey.

6. These issues are not unique to the United States. See, for example, Atkinson, Piketty, and Saez (2011), who provide a multinational and longer-run view of rising income inequality. 
Figure 1. The Top Wealth Shares, 1989-2013

\section{Top 1 percent wealth shares}

Percent

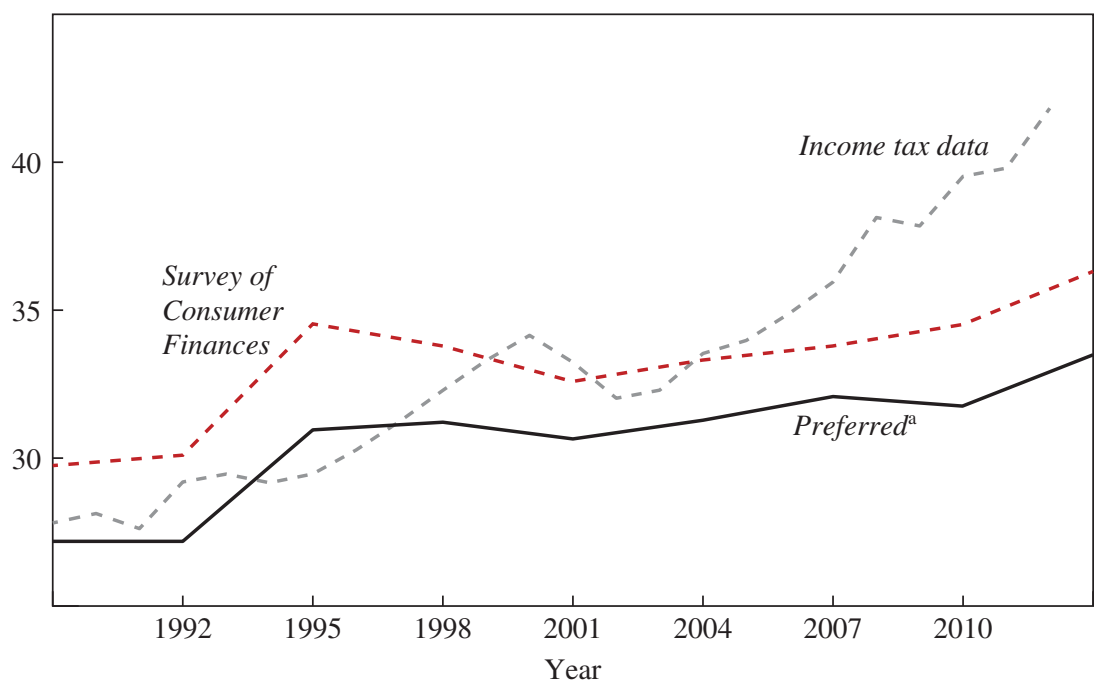

Top 0.1 percent wealth shares

Percent

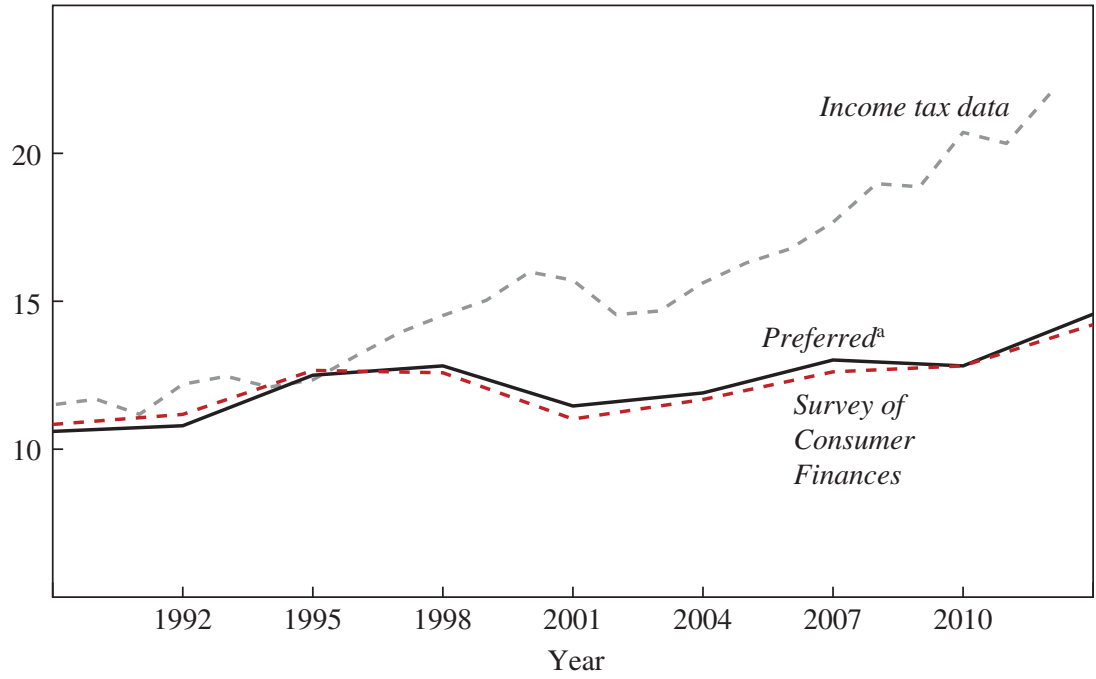

Sources: Survey of Consumer Finances; Saez and Zucman (2016).

a. Our preferred wealth measure is the Survey of Consumer Finances measure, plus defined-benefit pension wealth, plus the wealth of the members of the Forbes 400 . See the text and the online appendix for details. 
Figure 2. The Top Income Shares, 1988-2012

\section{Top 1 percent income shares}

Percent

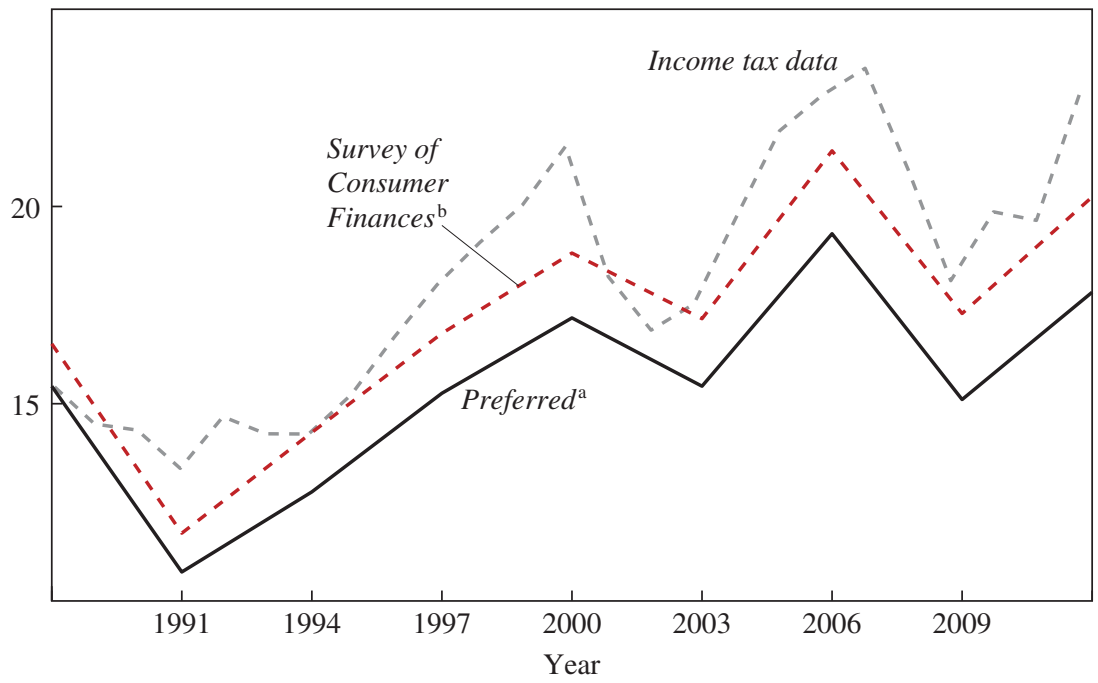

Top 0.1 percent income shares

Percent

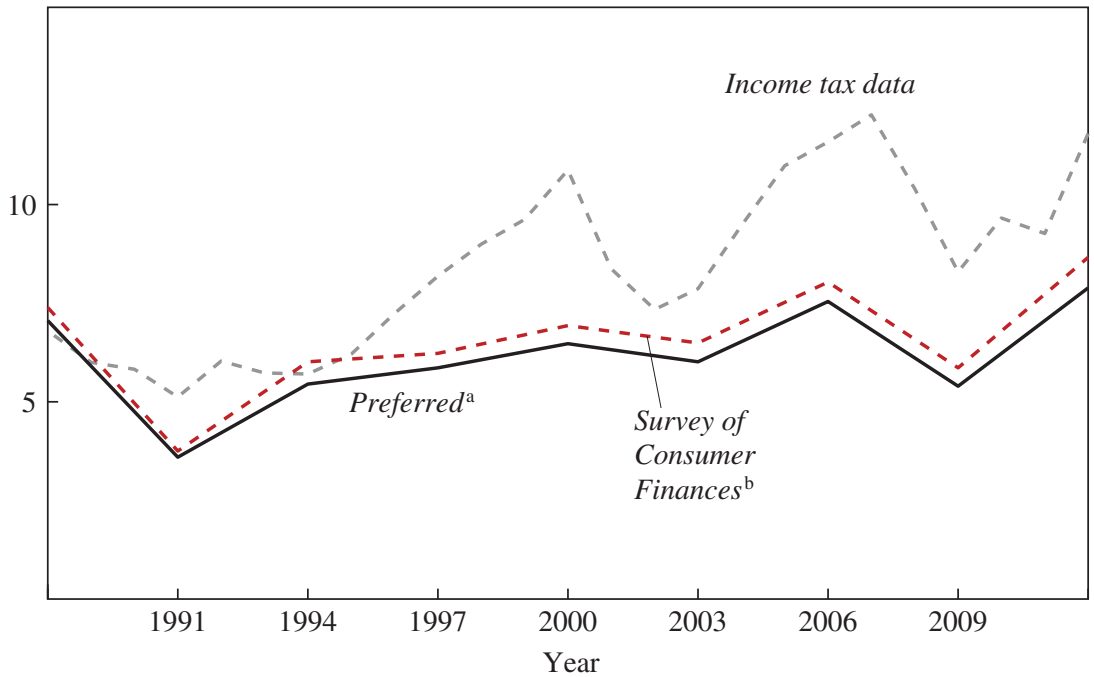

Sources: Survey of Consumer Finances; Piketty and Saez (2003).

a. Our preferred income measure is the Survey of Consumer Finances measure, plus the value of employerprovided health insurance and government health care programs, plus the value of in-kind government transfers, plus the imputed incomes of the members of the Forbes 400. See the text and the online appendix for details.

b. The Survey of Consumer Finances collects income data for the calendar year preceding each triennial survey. 
paper we document that resolving these conceptual and measurement differences also resolves most of the difference in wealth and income concentration estimates from the two data sources.

In the case of wealth, concentration measures derived from administrative income tax records can yield improbable results and are sensitive to model assumptions. There are no administrative wealth data in the United States, so "administrative" estimates of wealth must infer wealth by capitalizing taxable income through a common rate of return on asset types. Wealth inferred in this way is heavily dependent on model parameters, and wealth share estimates can be sensitive to small deviations in assumed rates of return. For instance, the return on fixed-income assets of the wealthy assumed by Saez and Zucman (2016) implies as much as four times more wealth than does a market rate of return, and two times more wealth than rates of return estimated from estate tax filings. When wealth concentration is reestimated, changing only the return on fixed-income assets to either of these alternate rates of return, the trend and level of wealth concentration over the past 10 years are identical to SCF estimates that are constrained to use administrative data wealth concepts and units of measurement. Essentially, the entire difference in wealth concentration estimates is due to assumptions about measurement and data construction.

Adjusting income concepts and the unit of measurement generally also brings estimated income shares in the administrative tax data (Piketty and Saez 2003) and the SCF into agreement. However, neither data set is able to provide a full accounting of total personal income in the United States.

The central goal of this paper, then, is to go beyond reconciliation and provide preferred top share estimates of wealth and income. These preferred estimates marry the concepts from macro data to micro data and cover the full target population, which is all U.S. families. We provide evidence that augmenting the SCF gets us close to this ideal. Overall, the top share estimates derived in this paper show much lower and less rapidly increasing top shares than the widely cited values from the Saez and Zucman (2016) and Piketty and Saez (2003) studies mentioned above (figures 1 and 2). ${ }^{7}$

To produce new and improved estimates of wealth and income concentration, we begin by considering the preferred concept of wealth and

7. The top share estimates from Piketty and Saez (2003) and Saez and Zucman (2016) are regularly updated and published in the World Wealth and Income Database, which is maintained by Facundo Alvaredo and Tony Atkinson, along with Thomas Piketty, Emmanuel Saez, and Gabriel Zucman. This database is accessible at www.wid.world. 
income from an economic point of view. The preferred concept of wealth includes all assets over which a family has a legal claim that can be used to finance its present and future consumption. This concept mirrors the household wealth concept used in the Financial Accounts of the United States (FA) because it includes a family's liabilities and both its financial and nonfinancial assets, as well as its rights to defined-benefit (DB) pensions. ${ }^{8}$ The preferred income concept includes all income received by a family, whether or not it is fully taxed, partially taxed, or untaxed. This concept mirrors the personal income category in the National Income and Product Accounts (NIPA). Both the FA and NIPA are aggregate data, however, and micro data sets are needed for distributional analysis.

Several challenges must be confronted when estimating wealth and income distributions with micro data, such as the SCF and the administrative tax data. The first is that micro data sets do not include every FA wealth concept or every NIPA income concept. Untaxed income, such as the value of employer-provided health insurance and some government transfer income, is never collected in the income tax data and is only sometimes collected in a survey. The SCF wealth estimate typically does not include DB pensions, while most forms of consumer debt cannot be estimated when wealth is inferred from income tax data.

A second estimation challenge concerns differences in population coverage and measurement between these micro data sets. Household surveys are generally thought to reliably cover the full income and wealth distribution, save perhaps the very top. Administrative tax data can reliably cover the top, but coverage suffers at the bottom of the distribution because many families are not required to file tax returns.

Differences in measurement also arise in the units of analysis, which are tax units in the income tax data and the family in a household survey. There are many more tax units (161 million) than families (122 million). Families in the bottom 99 percent are often split into multiple tax units, but a tax unit in the top 1 percent is almost always a family. Counting the top 1 percent (1.61 million) of tax units, then, effectively includes more families than counting the top 1 percent (1.22 million) of families in a survey.

In addition to the conceptual, coverage, and unit-of-analysis difficulties that plague efforts to measure either income or wealth concentration, estimating top wealth shares using administrative tax data introduces yet another potential source of errors. Wealth can only be measured indirectly

8. The Financial Accounts of the United States (Statistical Release Z.1) are available from the Federal Reserve Board (http://www.federalreserve.gov/releases/z1). 
in income tax data-meaning that wealth is inferred mainly by "capitalizing" income flows- which is at the heart of the approach taken by Saez and Zucman (2016). ${ }^{9}$ In a survey like the SCF, wealth is measured directly by asking families about their balance sheets. Accounting for these measurement differences by constraining the SCF to match administrative tax data concepts resolves the discrepancies between the various top wealth share estimates. In particular, the evidence given here and by Wojciech Kopczuk (2015b) shows the sensitivity of wealth inferred from income tax data.

By marrying the concepts from the macro data to the micro data, we can provide preferred top share estimates that cover the full target population: all U.S. families. We provide evidence that augmenting the SCF gets us close to this ideal. We first demonstrate that the SCF represents the full family income and wealth distribution, save for the Forbes 400. By augmenting the SCF household survey along these lines, and by aligning the preferred wealth and income concepts and measurement laid out above, we derive preferred top share estimates.

Our preferred estimates for wealth shares at the top are lower and growing more slowly than in the widely cited capitalized administrative tax data from Saez and Zucman (2016), but this is mostly for methodological reasons, especially the specific capitalization factors used to estimate certain types of wealth (cited above). Indeed, our preferred top wealth share estimates are quite similar to the published SCF values-because one adjustment, adding the Forbes 400, pulls up the SCF top wealth shares; and another adjustment, distributing DB pension wealth, pushes top shares down by a similar amount (figure 1).

Our preferred estimates for top income shares are also lower and rising less rapidly than the recent and widely cited estimates from Piketty and Saez (2003), which were derived from administrative tax data (figure 2). However, those administrative tax data income shares are similar (on an equivalent basis) to SCF top shares, and thus the preferred income top shares are also lower and growing more slowly than published estimates based on the SCF. The differences in levels for incomes at the top (by income) are affected to some extent by the choice of measuring incomes for tax units versus families; but in the end, the wedge in the trends between our preferred and the available top income share estimates

9. Greenwood (1983), among others, provided the foundational work for the capitalization approach. Capitalization is used in conjunction with other approaches in the SCF sampling procedure. See the online appendix to this paper and Kennickell and Woodburn (1999) for more details. The online appendixes for this and all other papers in this volume may be found at the Brookings Papers web page, www.brookings.edu/bpea, under "Past Editions." 
is largely driven by the failure of the available micro data to capture cash and in-kind transfers, which are growing rapidly as a share of total income over time. ${ }^{10}$

The reasons for focusing on both wealth and income in one paper are mostly practical. Wealth and income are strongly correlated, so the decisions about how to measure top wealth shares are not neatly separated from the decisions about how to measure top income shares. Indeed, the principle of capitalizing specific income flows forms the basis for wealth inferences in the administrative income tax data and is also used to infer who should be surveyed in the SCF. ${ }^{11}$ This process ties top wealth and income share estimates together in an important way.

In addition to the statistical issues, there is also an important conceptual reason for considering both wealth and income concentration in the same paper. Neither income nor wealth concentration tells us everything we want to know about key questions in political economy; but together, the two tell us most of what we want to know. The top income shares are interesting because changes in the flow of returns from current production suggest that something may be amiss in how factor payments are being determined. And the top wealth shares are interesting above and beyond top income shares because disproportionate or increasing control over the level of economic resources may reflect increasing and persistent income concentration-assuming the rich are saving more of their increased incomes - but it could also be driven by trends in relative asset prices and heterogeneous returns on assets. Though dynastic wealth may be less important today than in the past in determining the wealthiest (Kopczuk 2015a), both wealth and income concentration may reflect and shape inequality of opportunity (Yellen 2014).

Some distributional shifts in income might be attributable to fundamental economic factors such as skill-biased technological change, but this probably does not explain increased income concentration within the top 1 percent. Institutional factors may be having an impact across factors of production generally (capital versus labor) and within factors (managerial versus production labor), such that those with the highest incomes are able

10. The SCF, administrative income tax, and our preferred measures of wealth and income can be biased by mismeasurement. The mismeasurement in the SCF can come from a respondent misreporting wealth or income components, and the income tax data can suffer from mismeasurement by tax avoidance and evasion. For this to matter in the analysis of top share trends, however, mismeasurement must have changed in a nonrandom way over our time series.

11. This is described in the online appendix. 
to capture even higher future shares. Conversely, changes in the way that labor is compensated may be mechanically affecting measured top income shares if (unmeasured) health care and retirement costs are disproportionately pushing down incomes for the nonrich.

One specific concern is that wealth concentration may feed on itself if undue political influence is being exercised by those who can (sometimes independently) finance election campaigns and generate an even more favorable tax or regulatory environment for themselves in subsequent periods. The primary concerns about the effects of rising wealth inequality involve investment and economic growth. Rising wealth concentration may intensify financing constraints for the nonwealthy, affecting investment in education, entrepreneurship, and other types of risk-taking for those with diminished resources. As with incomes, however, it is important to consider what may be driving the estimates of top wealth shares before recommending policies to address those trends.

Identifying the potential biases in top wealth and income share estimates begins with a comprehensive discussion of data and concepts, which is the subject of section I of this paper. Section II then focuses on deriving the preferred estimates for top wealth shares, and section III focuses on top income shares. For both wealth and income, in the course of generating the preferred top shares, we also show how to reconcile the existing SCF and administrative tax data top share estimates. The reconciliation shows that the first-order divergence between the SCF and administrative tax data is basically conceptual in nature, and not a problem of population coverage. The reconciliations generally involve the differences between micro and macro concepts, the unit of analysis, whether and how certain groups are represented in the micro data, and potential survey reporting for different types of incomes.

\section{Measuring Wealth and Income Concentration: Concepts and Data Sources}

Our starting points for measuring top wealth and income shares are the aggregate concepts and estimates of household sector net worth and income built into the Financial Accounts of the United States and the National Income and Product Accounts. The distributional analysis itself is based on two distinct (but related) micro data sets. Top income and wealth shares are first estimated using the Survey of Consumer Finances, a household survey micro data set collected by the Federal Reserve Board. The top income and wealth shares are then estimated from administrative income tax data 
produced by the Statistics of Income (SOI) Division of the Internal Revenue Service. These SOI administrative micro tax data are the direct source of the top income shares in Piketty and Saez (2003), the indirect source of the top wealth shares in Saez and Zucman (2016), and the basis for drawing the sample of SCF high-end respondents.

This section describes how the various wealth concepts, income concepts, aspects of population coverage, and units of analysis compare and contrast across these four data sets. Thus, it sets the stage for developing preferred estimates of the top wealth shares in section II, and the top income shares in section III.

\section{I.A. Wealth Concepts and Data}

Our starting point for measuring wealth concentration is the concept of net worth owned by the household sector, as embodied in the FA. ${ }^{12}$ From an economic point of view, this concept of wealth includes all assets over which a family has a legal claim that can be used to finance its present and future consumption. The net worth of a family is its assets net of liabilities.

This definition excludes some wealth under the control of a familymost notably charitable foundations-as well as expected future Social Security payments. We exclude foundations because a family does not consume goods and services from the assets in the foundation, even though they may be able to consume (nontangible) reputational benefits. ${ }^{13} \mathrm{We}$ exclude expected future net Social Security benefits mostly for practical reasons. The Social Security wealth measure that one would like to capture is the present value of expected future benefits less expected future taxes, but one would need to make a number of assumptions and projections to actually implement those calculations, beginning with whether or how promised but unfunded benefits will actually be paid. However, given the generally progressive nature of Social Security, it is clear that adding

12. Most of the discussion here is focused on concepts in FA table B.101, though the reconciliation between SCF and FA aggregates also involves details on pensions from subtables, such as table L.117. For details on the SCF and FA reconciliation, see the online appendix, Henriques and Hsu (2014), and Dettling and others (2015).

13. The SCF collects information on the value of such charitable trusts and foundations, and wealth held in these entities. Including these assets along with SCF household wealth would have only marginal effects on our top share estimates presented later. In the 2010 SCF, for example, the wealth share held by the top 1 percent would increase from 34.5 to 34.7 percent. Further, these assets only constitute about 9 percent of the total assets held by nonprofits (authors' calculations; McKeever 2015). 
estimates of Social Security wealth would push the more expansive concentration numbers below our preferred estimates. ${ }^{14}$

Our unit of organization is the family, rather than the individual or tax unit, because decisions about future and current consumption are usually made with at least some weight from and consideration for all members of the immediate family. ${ }^{15}$ Tax units are frequently families, but tax-filing rules often split one family into many tax units.

There is little difference in the conceptual measure of wealth across the micro data (SCF and administrative tax) and macro data (FA). The FA include assets held in the nonprofit sector, and though it is possible to separate nonprofit real estate holdings, financial assets owned by nonprofits are always included in the overall household net worth measure in the FA. ${ }^{16}$

There are, however, key differences in how various balance sheet items are estimated in the two sets of micro data, as shown in table 1 . The most notable difference is that income-generating financial and business assets are estimated in the administrative tax data by applying "gross capitalization" to the observed income flows, while those assets are estimated directly in the SCF through the survey questionnaire. A key assumption in gross capitalization is that all assets of a given type earn a single rate of return, and thus there is a direct relationship between the stock and the flow. ${ }^{17}$

Implementing the gross capitalization approach also requires choosing a gross capitalization factor for each asset type, which Saez and Zucman (2016) solved by using the ratio of a given FA asset balance for the corresponding aggregate administrative tax data flow. This approach generates

14. Devlin-Foltz, Henriques, and Sabelhaus (2016) estimate the present value of Social Security benefits for the cohort of near-retirees in 2013, for whom future taxes are inconsequential, and show that inequality in total retirement claims is effectively eliminated when Social Security is included. Specifically, the ratio of average total retirement claims (individual retirement accounts, defined-contribution accounts, and the present value of definedbenefit pensions and Social Security) to average income is roughly constant across most lifetime income groups, and lowest at the very top of the distribution.

15. "Family" is defined here as the economic core of a household and all people at that address whose finances are intertwined with that person.

16. Net worth is generally calculated as households' total assets (financial and nonfinancial) minus their total liabilities (debts to other sectors). However, because households effectively "own" the other private sectors (such as corporations) through ownership of equities and debt, household sector net worth effectively represents all private net worth claims.

17. Fagereng and others (2016) test this assumption and reject it. Families at the upper tail of the wealth distribution have much higher rates of return than other families. Tabulations from the SCF are consistent with this finding as well. 
Table 1. Measuring Household Wealth in the Survey of Consumer Finances and Capitalized Administrative Tax Data

\begin{tabular}{|c|c|c|}
\hline Concept & $\begin{array}{l}\text { Survey of Consumer } \\
\text { Finances }\end{array}$ & Administrative tax data \\
\hline $\begin{array}{l}\text { Owner-occupied } \\
\text { housing }\end{array}$ & $\begin{array}{l}\text { Direct report on value of } \\
\text { primary residence }\end{array}$ & $\begin{array}{l}\text { Allocate FA housing total by } \\
\text { capitalizing property tax } \\
\text { paid on Form } 1040 \text { (among } \\
\text { itemizers) }\end{array}$ \\
\hline + Businesses & $\begin{array}{l}\text { Direct report on value of } \\
\text { businesses }\end{array}$ & $\begin{array}{l}\text { Allocate FA total by capitalizing } \\
\text { business income on Form } \\
1040\end{array}$ \\
\hline $\begin{array}{l}+ \text { Nonretirement } \\
\text { financial }\end{array}$ & $\begin{array}{l}\text { Direct report on value of } \\
\text { checking accounts, sav- } \\
\text { ings accounts, certificates } \\
\text { of deposit, mutual funds, } \\
\text { directly held stocks, } \\
\text { annuities, trusts, managed } \\
\text { accounts }\end{array}$ & $\begin{array}{l}\text { Allocate FA total by capital- } \\
\text { izing interest, nontaxable } \\
\text { interest, dividend income } \\
\text { on Form } 1040\end{array}$ \\
\hline - Mortgage liabilities & $\begin{array}{l}\text { Direct report on value of } \\
\text { mortgage balances }\end{array}$ & $\begin{array}{l}\text { Allocate FA outstanding } \\
\text { mortgages by capitalizing } \\
\text { mortgage interest deduction } \\
\text { reported on Form } 1040\end{array}$ \\
\hline - Other liabilities & $\begin{array}{l}\text { Direct report on value of } \\
\text { lines of credit, car loans, } \\
\text { education debt, credit } \\
\text { cards, other consumer } \\
\text { debt }\end{array}$ & Unallocated \\
\hline $\begin{array}{l}\text { + Defined-contribution } \\
\text { (DC) retirement }\end{array}$ & $\begin{array}{l}\text { Direct report on value of } \\
\text { individual retirement } \\
\text { accounts, DC pensions } \\
\text { on current and past jobs }\end{array}$ & $\begin{array}{l}\text { Allocate FA pension total using } \\
\text { wages and pension payments } \\
\text { (defined-benefit [DB] and } \\
\text { DC are not separated) }\end{array}$ \\
\hline $\begin{array}{l}=\text { Marketable net worth } \\
+ \text { DB retirement }\end{array}$ & $\begin{array}{l}\text { SCF Bulletin concept } \\
\text { Allocate FA DB total using } \\
\text { wages and direct report } \\
\text { on plan participation and } \\
\text { benefits }\end{array}$ & $\begin{array}{l}\text { Allocate FA pension total using } \\
\text { wages and pension pay- } \\
\text { ments (DB and DC are not } \\
\text { separated) }\end{array}$ \\
\hline $\begin{array}{l}=\text { Private net worth } \\
+ \text { Unallocated } \\
\text { liabilities }\end{array}$ & Preferred estimate & $\begin{array}{l}\text { Saez and Zucman (2016) } \\
\text { estimate }\end{array}$ \\
\hline
\end{tabular}


micro-level wealth totals that, by construction, match the macro-level wealth totals. However, any mismatch between the micro and macro data concepts will lead to bias in capitalization factors and a misallocation of wealth. For example, if the FA aggregate for some asset includes holdings of nonprofit institutions, whereas the micro income flows do not, then too much wealth will be assigned (per $\$ 1$ of income) at the micro level. Similarly, if the micro data miss small income flows-say, the modest interest earned on checking and savings accounts in a low-interest-rate environment- the corresponding FA assets will be assigned only to those families with large and reported interest flows. These possibilities are more than theoretical, as we show later in the paper that implausible capitalization factors are the key to understanding differences between the survey and administrative tax data estimates for top wealth shares.

Assets that do not generate observable income flows, such as housing and pension wealth, are allocated in the gross capitalization framework using correlations with other observables in the administrative tax data, such as property taxes and wages, and are benchmarked to available external sources, such as the SCF or published Internal Revenue Service statistics. Again, those assets are measured directly in the SCF, along with nonmortgage liabilities for which there are no useful correlates in the tax data that can be used for distribution. The one asset category that requires inference in the SCF is DB pension wealth. The approach for distributing future DB claims in our preferred top share estimates involves using the survey reports of wages, current DB coverage, and years in a plan for those still working, and current benefits for those already receiving benefits. ${ }^{18}$

\section{I.B. Income Concepts and Data}

Our starting point for estimating top income shares is the concept of personal income (PI), as measured in the NIPA. ${ }^{19} \mathrm{PI}$ is a very broad concept, and is meant to capture all forms of income received by individuals, nonprofit institutions serving households, private noninsured welfare funds, and trust funds. It includes income that is taxed, partly taxed (such as Social Security benefits), and untaxed (mostly transfers, whether cash or in-kind). In particular, we augment the family-level income data in the

18. The algorithm for distributing SCF DB pension wealth is described in the online appendix and in greater detail by Devlin-Foltz, Henriques, and Sabelhaus (2016).

19. Most of the discussion here is focused on broad income concepts in NIPA table 2.1, though a comprehensive reconciliation with the micro data also involves details from other parts of the NIPA, such as tables 1.12, 3.12, 7.9, 7.10, 7.11, and 7.20. For a detailed reconciliation of NIPA and SCF incomes, see Dettling and others (2015). 
SCF — which already includes market income, Social Security benefits, and some transfers- to include estimates of employer health insurance benefits, Medicare benefits, Medicaid benefits, food stamps, and other in-kind transfer payments.

We recognize that there are a variety of ways to measure a "more complete" income (Congressional Budget Office 2014; Burkhauser, Larrimore, and Simon 2012; Burkhauser and others 2012; Smeeding and Thompson 2011), and that the definition of income may depend on the economic exercise. We take great comfort, however, from the fact that top income shares based on our measure of income have the same level and trend as the Congressional Budget Office's measure, which is another hybrid of administrative and survey data (see the online appendix for more detail).

In this section we discuss the conceptual differences between administrative tax data, the SCF, and NIPA, thereby establishing the underpinnings for our preferred top shares estimates presented later in the paper. Although our starting point for measuring top income shares is PI, we acknowledge that there are some irreconcilable differences between the micro and macro data, a key timing adjustment, and one notable addition on the micro side, for realized capital gains. ${ }^{20}$ These differences are highlighted in table 2 .

In many ways the SCF and administrative tax data are closely related, and are generally consistent with the concept of NIPA PI. Most forms of income from current production-including wages and salaries, business income, interest and dividends paid directly to persons, and other smaller types of "market" income-are conceptually (and empirically) similar in the two micro data sources. To some extent this is by construction, because the SCF income module invites respondents to refer to their income tax returns when answering those questions. The two sets of micro data are in turn mostly consistent with the NIPA in those categories, though NIPA makes adjustments for the underreporting of proprietors' incomes and imputes certain incomes, such as the rental value of owned housing and the value of financial services provided by banks.

20. One aspect of income concentration we do not (and cannot) address in this paper is the conceptual issue of what frequency should be used to measure top shares. Wealth is generally more straightforward, because concentration is measured at a point in time, though we will see frequency also plays a role there in terms of what can and cannot be measured. One can argue that income concentration should be measured at lower frequencies, in order to sort out transitory income effects, and also to address some of the conceptual issues we raise, such as measuring retirement income when the claim is established versus when the income is actually received. The decision here to focus on annual measures is largely driven by what data are available over long periods. 


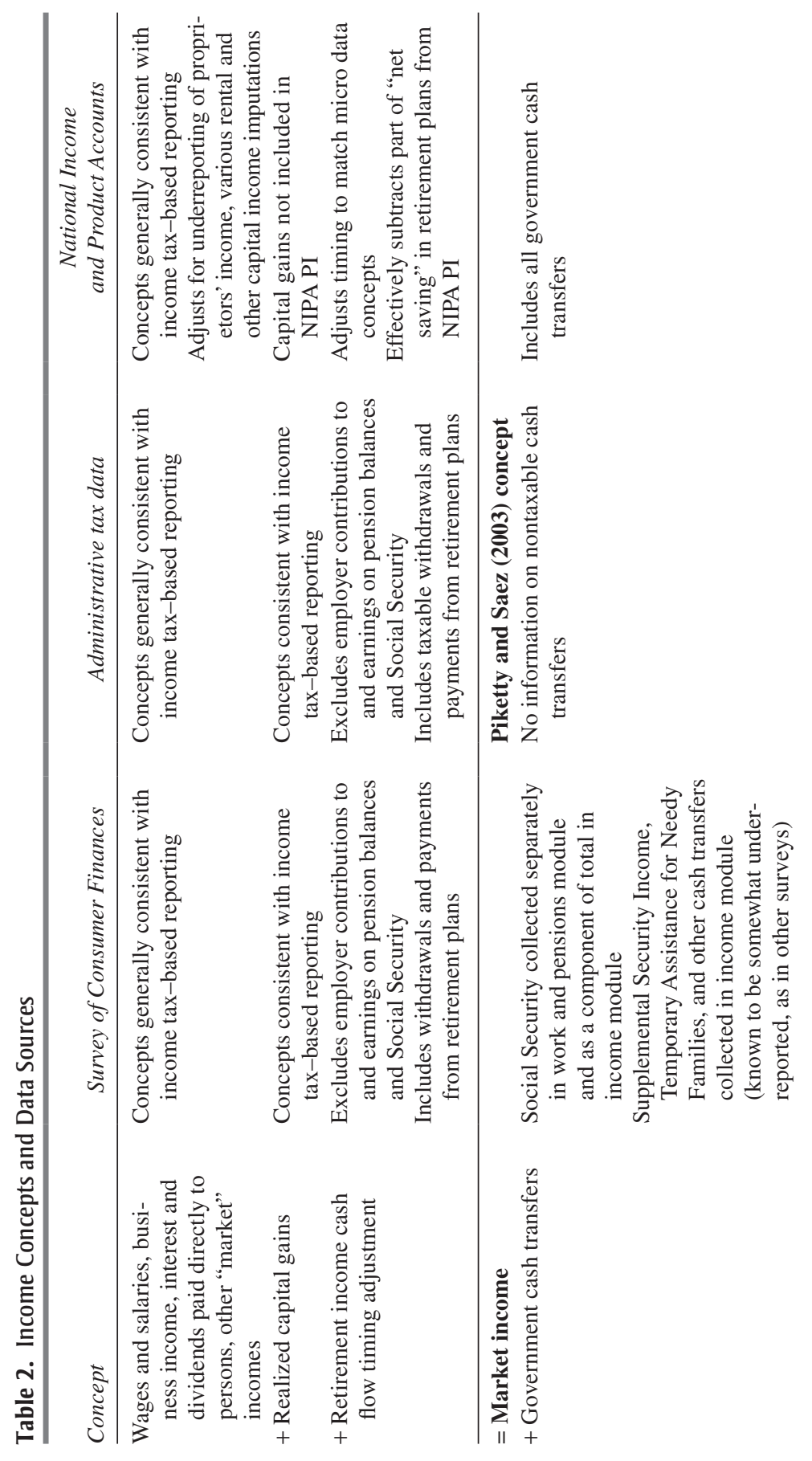




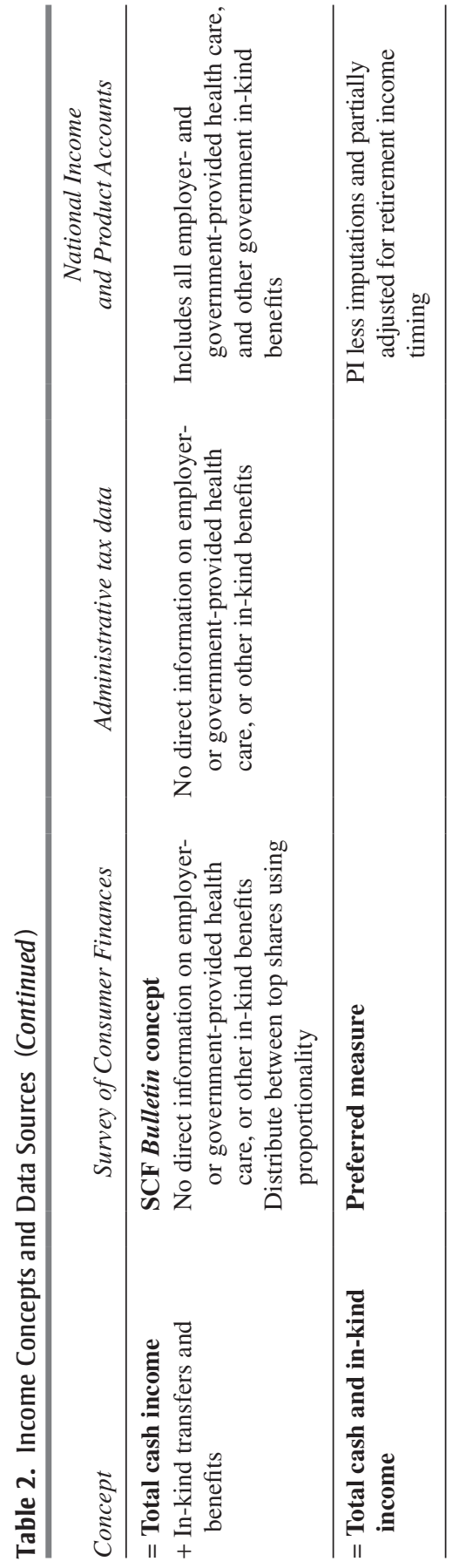


The two sets of micro data both count realized capital gains as part of the core income measure, while NIPA does not count capital gains in PI. The NIPA exclusion is based on fundamental national income accounting principles. That is, capital gains are not tied directly to current production; nor do they constitute a transfer from one sector to another. However, for the purpose of measuring top income shares, we choose to include realized gains because they do constitute a flow of current resources over which the family has control.

The treatment of retirement incomes is also different in the micro and the macro data. In the NIPA, and again, based on the principle that incomes should be derived from current production or arising from transfers across sectors, retirement income occurs when employers contribute to retirement plans on their employees' behalf, or when the retirement assets generate interest and dividends. The actual payment of retirement benefits is a mixed bag in the NIPA, with withdrawals and benefits paid from private plans not included, and payments from government plans showing up as transfer income. In the micro data, employer contributions and capital income earned by retirement plans are generally unobserved, but withdrawals are (though to a differing degree in the SCF and administrative tax data) generally observed.

To some extent the appropriate treatment of retirement income cannot be separated from the frequency over which incomes are being measured. On a lifetime basis, it would not matter whether private retirement income was counted, as it was accrued or when it was paid out, but the distinction does matter when using annual data. Given the availability of cash floworiented micro data at an annual frequency, the top shares estimates we present are based on realized benefits, which implicitly adjusts the NIPA PI concept for a portion of "net saving" in retirement plans, where net saving is new contributions plus interest and dividends earned on plan assets, less pension benefits paid. However, the fact that some new employee contributions (employee-paid Social Security taxes) to retirement plans are still counted (in the micro data) as part of nonretirement income means that the adjustment is only partial.

The more substantial conceptual differences between our preferred income top share estimates and those available in the micro data are associated with nontaxable government transfers and in-kind compensation. In principle, the SCF captures government cash transfers, but the administrative tax data by construction do not, and the rising share of transfers in NIPA PI means that less total income is being distributed over time when 
using either micro data set. ${ }^{21}$ Neither the SCF nor the administrative tax data make any adjustment for in-kind compensation and transfers, which, especially through employer-provided health care plans and the major government health care programs, have roughly doubled as a share of total NIPA PI since 1988. Our conceptually preferred measure for top income shares allocates these missing income pieces, which brings our overall income concept close to NIPA PI. The remaining conceptual differences are in the imputations and retirement income timing, as discussed above.

\section{I.C. Population Coverage and Units of Analysis}

The population of interest in our analysis of top wealth and income shares is all U.S. households. In some ways, this is a simplistic statement, because households are the ultimate claimants on all private incomes and wealth. However, there is substantial private income received and wealth owned by nonprofit institutions that should be excluded, and that is not completely feasible to sort out given the available macro data. In addition to these sectoral coverage issues, there are also differences in population coverage and measurement across the distribution of households, with administrative income tax data generally perceived to be more accurate at the top of the distribution, and household surveys like the SCF thought to provide better coverage at the bottom. These comparisons are further confounded by the differences in the unit of observation across the micro data, with the administrative data collected for tax units, and the survey data collected for households.

Table 3 summarizes the differences in population coverage and the unit of analysis across the four data sets with which we are working. The first key difference between the two sets of micro data is the unit of analysis. In the U.S. income tax data, observations are for tax filing units, not families. The number of tax units (about 161 million in 2012) is approximately 30 percent higher than the number of families (122 million in the SCF). ${ }^{22}$

21. The evolving differences in the concept of income in administrative versus survey data are also emphasized by Burkhauser, Larrimore, and Simon (2012); and by Armour, Burkhauser, and Larrimore (2014).

22. Statistics on tax units here and later in the paper are from Emmanuel Saez's website, in the regularly updated file http://eml.berkeley.edu/ saez/TabFig2014prel.xls. The actual unit of observation in the SCF is the "primary economic unit," which is somewhere between the census "family" and "household" concepts. See the appendix to Bricker and others (2014) for a precise definition. The number of families in the SCF is benchmarked to that found in the Current Population Survey. The number of tax units includes an estimate of nonfilers. 
Table 3. Population Coverage and the Unit of Analysis across Income and Wealth Data Sets

\begin{tabular}{|c|c|c|c|c|}
\hline & $\begin{array}{l}\text { Survey of } \\
\text { Consumer } \\
\text { Finances }\end{array}$ & $\begin{array}{l}\text { Administrative } \\
\text { tax data }\end{array}$ & $\begin{array}{l}\text { National } \\
\text { Income and } \\
\text { Product } \\
\text { Accounts }\end{array}$ & $\begin{array}{l}\text { Financial } \\
\text { Accounts }\end{array}$ \\
\hline $\begin{array}{l}\text { Unit of } \\
\text { analysis }\end{array}$ & Families & Tax units & Aggregate & Aggregate \\
\hline Coverage & $\begin{array}{l}\text { Entire non- } \\
\text { institutional } \\
\text { population } \\
\text { Corrects for low } \\
\text { participation } \\
\text { at high end } \\
\text { using list } \\
\text { sample } \\
\text { Excludes Forbes } \\
400\end{array}$ & $\begin{array}{l}\text { Tax-filing popu- } \\
\text { lation only } \\
\text { Supplement } \\
\text { with informa- } \\
\text { tion on non- } \\
\text { filers from } \\
\text { other data } \\
\text { sources }\end{array}$ & $\begin{array}{l}\text { Households } \\
\text { and nonprofit } \\
\text { institutions }\end{array}$ & $\begin{array}{l}\text { Households } \\
\text { and nonprofit } \\
\text { institutions } \\
\text { Possible to } \\
\text { separate out } \\
\text { nonprofit } \\
\text { holdings of } \\
\text { real estate }\end{array}$ \\
\hline
\end{tabular}

Most of the tax units at the very top are also families, meaning that many of those observed as a single family in the survey data but multiple tax units in the tax data are found in the bottom 99 percent of the wealth and income distribution. In the 2010 SCF, for example, fewer than 3 percent of coupled families in the top 1 percent filed separately, while about 17 percent of couples in families in the bottom 99 percent filed separately. The implication, then, is that any top share fractile estimate is effectively based on a population that may include 30 percent more family units than the fractile suggests.

There are many reasons to prefer the household (or family, which is close to household) as the unit of analysis for measuring top wealth and income shares. Many of the tax units residing in multiple-tax-unit families are dependent filers with very low incomes, and therefore they are effectively sharing resources with the other members of the household (usually their parents) who are able to claim them on their taxes. The same can be argued for unmarried partners sharing living arrangements and resources but filing taxes separately. It makes sense to pool their resources when characterizing their share of income or wealth. One can argue that roommates who are not sharing resources could be treated as separate units; but in the end, the issue is really about what one means when measuring the wealth or income shares of "the" top 1 percent. Is this the top 1.22 million families in 2012, or the top 1.61 million tax units? Our preferred estimate is 
based on families, and the substantial difference between the total counts of families and tax units will turn out to be a key driver of the wedge between existing estimates of the levels of top wealth and income shares.

Sectoral coverage matters when comparing the SCF to administrative tax data, and between the two sets of micro data and the two sets of macro data. The micro data sets do not attempt to measure wealth and income received by nonprofit institutions, and the only available adjustment on the macro side is in the FA balance sheet measure, which separates the real estate holdings of nonprofit institutions. This sectoral overlap becomes important when thinking about the total income or wealth in the denominator of the concentration measures, and whether, for example, a given income flow or asset holding should be allocated to a given top shares group or spread more evenly throughout the distribution. In particular, the capitalization approach to estimating top wealth shares relies on administrative income tax data flows calibrated to FA levels. This approach will assign nonprofit, nonhousing asset holdings across groups based on measured incomes, exacerbating any differences in actual wealth holdings.

There is also a key difference between the micro data sets in population coverage, and this has a potentially first-order bearing on estimated top shares. The goal of the SCF is to survey the entire noninstitutional population—using a standard, nationally representative, area probability sample-along with the "list" sample derived from administrative tax returns, designed to correct for low survey response rates among wealthy families. ${ }^{23}$ The members of the Forbes 400 in the year the sample is drawn are explicitly excluded from the SCF sample..$^{24}$ In our preferred top wealth and income share estimates, we add in the Forbes 400, but there is some question as to whether the SCF captures the rest of the top of the distribution, particularly those just below the Forbes 400 (see more on this in the next section).

The population coverage for administrative income tax data is necessarily limited to the population that files income taxes. Although there are many more tax units than there are families, there are many families

23. See the online appendix for a detailed discussion of the SCF sampling strategy. See Sabelhaus and others (2015) for direct estimates of the relationship between income and unit nonresponse. O'Muircheartaigh, Eckman, and Weiss (2002) provide a comprehensive description of the National Opinion Research Center's national area probability sample.

24. The sampling frame technically excludes other "public" figures as well, but assuming that those families have observational equivalents who are not public figures, there is no bias in the estimated wealth distribution. 
(low-income and retired) where no individual or couple is required to file a tax return. Indeed, of the 161 million estimated tax units in 2012, only 145 million actually filed tax returns. Using other household survey data, Piketty and Saez (2003) supplement the tax-based incomeconcentration measures by increasing the denominator (total income) to account for nonfilers. ${ }^{25}$

Both the SCF and the administrative income tax data face challenges vis-à-vis population coverage. The coverage challenge for the administrative tax data is mostly about nonfilers, and, to some extent, the coverage problems cannot be cleanly separated from the concept of income being measured, because the income composition of nonfilers is very different than the income composition of filers. The SCF also faces issues in capturing certain types of income, but the more immediate concern is whether the SCF actually captures the top of the distribution, as the sampling strategy is designed to accomplish.

\section{I.D. Does the SCF Capture the Top End?}

It is difficult to argue with the presumption that administrative tax data should provide better estimates of top wealth and income shares, because participation in the administrative data is required by law, and traditional household surveys are well known to suffer from an underrepresentation of very wealthy families ${ }^{26}$ In addition, administrative tax data are subject to audit, and thus (again) one presumes that income and other reporting will be more accurate in those data. Unlike most other household surveys, the SCF is designed to overcome the underrepresentation problem, because administrative tax data are used to select the sample, and rigorous targeting and accounting for wealthy families' participation assures that those families are properly represented. Also, SCF cases are reviewed for internal consistency (to some extent guided by the administrative sampling data), but this review process may fail to capture all reporting errors. In this subsection we show that the SCF does a very good job identifying and surveying wealthy families, and

25. They estimate that nonfilers have 20 percent of the average income of filers, where income is defined using the same taxable income concepts of the filers.

26. Sabelhaus and others (2015) show this is the case for the Consumer Expenditure Survey and Current Population Survey (CPS). Burkhauser and others (2012) show that at least some of the divergence between the CPS and administrative incomes is also due to top-coding of very high incomes in the CPS. Attanasio, Hurst, and Pistaferri (2015) use household budget data to study inequality; and in addition to the nonresponse issues, they find that reporting problems further confound consumption-based inequality estimates. 
there may be some downward bias in capturing certain types of income at the very top.

The SCF strategy begins with the view that a combination of survey and administrative data is better than either in isolation. The benefit of the survey component is straightforward, in that the data collector can control the population being studied and the specific wealth and income concepts being measured. However, for the purposes of studying top wealth and income shares, this benefit can be dwarfed by a failure to survey wealthy families. Measuring top wealth and income shares by expanding on simple random sampling in a traditional household survey is not a viable solution, because thin tails at the top lead to enormous sampling variability, and disproportional nonparticipation at the top biases down top share estimates.

The SCF effectively overcomes the problems of thin tails and differential nonparticipation by oversampling at the top, relying on administrative data derived from tax records, and by verifying that the top is represented using targeted response rates in several high-end strata. ${ }^{27}$ The SCF "list" sample actually comprises seven strata, where the first basically overlaps the address-based random sample, and the remaining strata identify increasingly wealthy groups of families up to (but not including) the Forbes 400. In very general terms, the top four strata in any given year, made up of roughly $1,000 \mathrm{SCF}$ families, effectively represent the top 1 percent of all families. The targeted response rates in the list sample do vary across strata in an expected manner, with participation rates falling as predicted wealth rises. The response rate in the wealthiest SCF stratum is about 12 percent, increasing to 25 percent in the second-wealthiest stratum, 30 percent in the third-wealthiest, 40 percent in the fourth- and fifth-wealthiest, and then about 50 percent in the two least-wealthy. These high-end response rates are considerably lower than the roughly 70 percent response rate observed in the SCF area probability sample.

The fact that participation rates are lower for very wealthy SCF families does not mean that the sample is biased by underrepresentation at the very top, however; it just reflects the fact that very wealthy families are

27. The online appendix has extensive details about the SCF sampling process. At the time the list sample was drawn, the most recent complete administrative data were those from two years before the survey year. The sample includes individual and sole proprietorship tax filings from the Internal Revenue Service's administrative tax data. These data are made available by the Statistics of Income Division in its annual publication no. 1304, available at https://www.irs.gov/uac/SOI-Tax-Stats-Individual-IncomeTax-Returns-Publication-1304-(Complete-Report). 
much more difficult to contact and then, given contact, are less likely to participate in the survey. Sample weights are systematically varied across the top strata in order to correct for the differential nonresponse. The important question is whether the families that eventually participate in the survey, thus representing their respective wealth stratum, are statistically distinguishable from sampled nonparticipants. ${ }^{28}$ Indeed, a regular step in the SCF's quality control process involves comparing and contrasting participants and nonparticipants within a stratum, in order to identify these sorts of potential biases. These comparisons are based on looking at administrative data incomes in the years preceding the survey. ${ }^{29}$

The administrative data underlying the SCF sampling are consistent with participants being representative of nonparticipants within each high-end stratum. The distributions of total incomes for SCF participants are similar to those of sampled nonrespondents (top panel of figure 3). Moving from the fourth-highest stratum to the highest stratum, one sees the substantial nonlinearity of incomes that characterize the top end, as each successive $\log$ scale for income shifts to the right in dramatic fashion. The range of incomes in the top four SCF strata completely cover the top 1 percent in an overlapping way-meaning, for example, that the top of the fourth-highest stratum overlaps with the bottom of the third-highest stratum, and so on. The capital income distributions of SCF respondents are also similar to those of nonrespondents (bottom panel of figure 3), and the nonlinearity in incomes as one moves from the fourth-highest to the highest stratum is even more dramatic. ${ }^{30}$

In general, statistical tests confirm the visual indication that participants and sampled nonparticipants within strata have very similar income distributions. The null hypothesis is that the two distributions come from the same underlying distribution, and the test statistics generally fail to the reject the null hypothesis, using a rank-sum test (either KolmogorovSmirnov or Wilcoxon). The specific results vary by year and across strata, but in the 2013 sample, the null hypothesis was rejected for only the secondhighest stratum for total income. ${ }^{31}$

28. See, for example, the discussion by Kennickell and Woodburn (1999).

29. One would perhaps like to compare respondent and nonrespondent incomes in the survey year itself, or to compare respondent-reported and administrative incomes for the survey year, but any such comparison would involve an implicit audit and thus violate the explicit agreement the SCF has with respondents to not audit their data.

30. Capital income here includes taxable and nontaxable interest, dividends, Schedule C and Schedule E business income, Schedule F farm income, and capital gains.

31. Results across income concepts, strata, and for earlier years are available upon request. 
Figure 3. Income Densities of the Top Strata of SCF Respondents and Nonrespondents, 2009-11

\section{Total income}

4th-highest stratum

Density

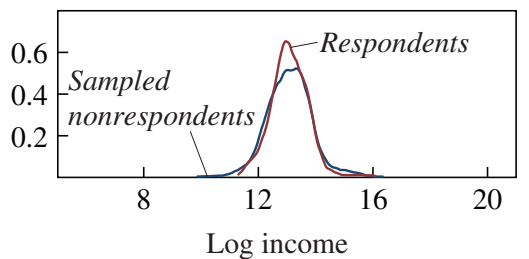

2nd-highest stratum

Density

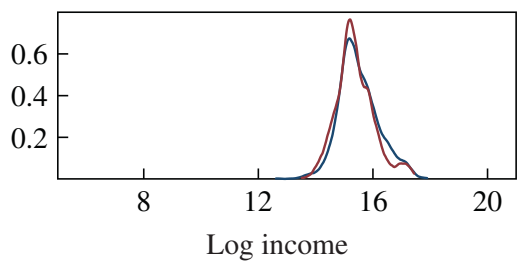

3rd-highest stratum

Density

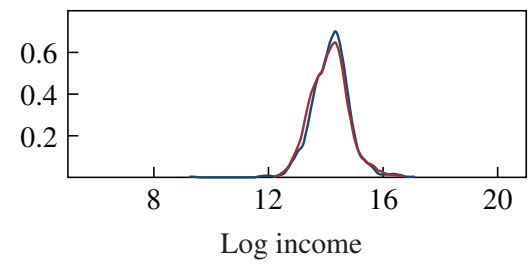

Highest stratum

Density

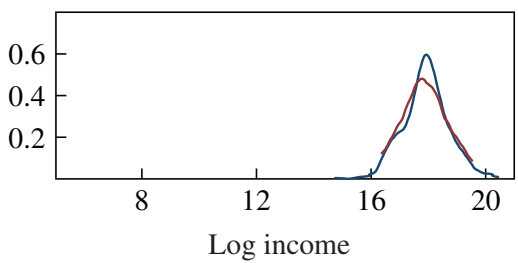

\section{Capital income}

4th-highest stratum

Density

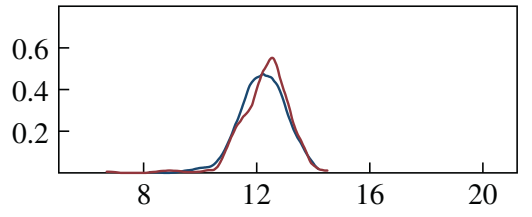

Log income

2nd-highest stratum

Density

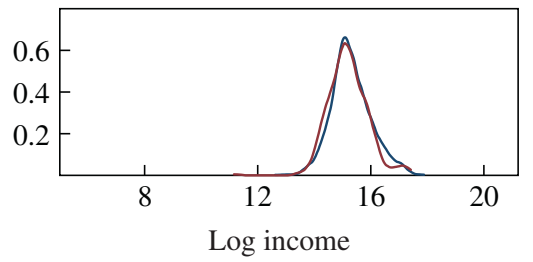

3rd-highest stratum

Density

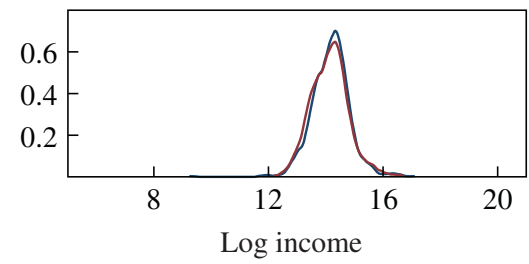

Highest stratum

Density

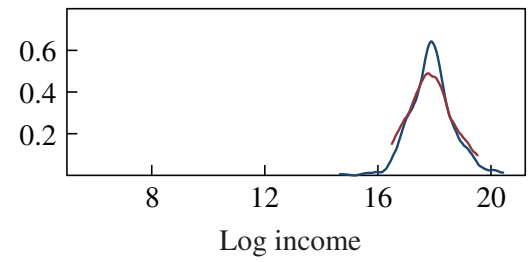

Source: Internal Revenue Service, Statistics of Income Division, individual and sole proprietorship data.

a. Incomes are 3-year averages and include capital gains. The sample includes the four highest strata, which fully encompass the top 1 percent of the predicted wealth distribution. The data for calendar years 2009-11 are associated with the sampling for the 2013 Survey of Consumer Finances. 
Focusing on the means of the distributions across strata, average total incomes for both participants and sampled nonparticipants in the fourthhighest stratum are generally about $\$ 500,000$, whereas the average total incomes in the highest stratum are above $\$ 50$ million (top panel of figure 4, shown, again, on a log scale). The averages for total income versus capital income only differ noticeably for the fourth-highest and third-highest strata (bottom panel of figure 4). In the top two strata, average total income is dominated by and effectively equivalent to capital income. As with differences in the distributions, one can test for differences in the means by income measure, stratum, and year. In general, the tests fail to reject the null hypothesis that the means for participants and sampled nonparticipants are the same..$^{32}$

In addition to average levels, one can also compare SCF respondents and nonrespondents in terms of observable presurvey income volatility. This metric also shows that SCF participants are similar to nonrespondents for both total income (top panel of figure 5) and capital income (bottom panel of figure 5). Income at the top is known to be much more volatile than in the rest of the income distribution, and the trend seems to be toward higher relative volatility at the top. ${ }^{33}$ In the SCF sampling data, for the top four strata covering the top 1 percent, about one-fourth of 2013 families experienced income changes below -50 percent or above +50 percent. The similarity between SCF respondents and nonrespondents means that potential distortionary effects from sampling families with very high or very low transitory income shocks is not a problem.

Although it would violate SCF protocol to directly evaluate the accuracy of any given SCF respondent's reported income, it is possible to get an estimate of reported income accuracy, on average, using two distributional comparisons against the entire SOI data set for a given survey year. The first approach is to compare the growth distribution of incomes reported by SCF respondents with the growth distribution observed in the SOI administrative data for families with comparable income levels. The second approach involves looking at how many SCF families report incomes above the published SOI thresholds, and how much income in total is reported by those in a given top income group. ${ }^{34}$

32. In 2013, the differences for the second-highest stratum were significant at the 5 percent level. Again, results for other years, income measures, and stratum are available upon request.

33. See, for example, Debacker and others (2013); Guvenen, Kaplan, and Song (2014); and Parker and Vissing-Jorgenson (2010).

34. We are grateful to the Internal Revenue Service's Statistics of Income Division for the unpublished growth rate distributions and threshold comparisons described here. 
Figure 4. Mean Incomes of the Top Strata of SCF Respondents and Nonrespondents, $2009-11^{\text {a }}$

\section{Total income}

Log income

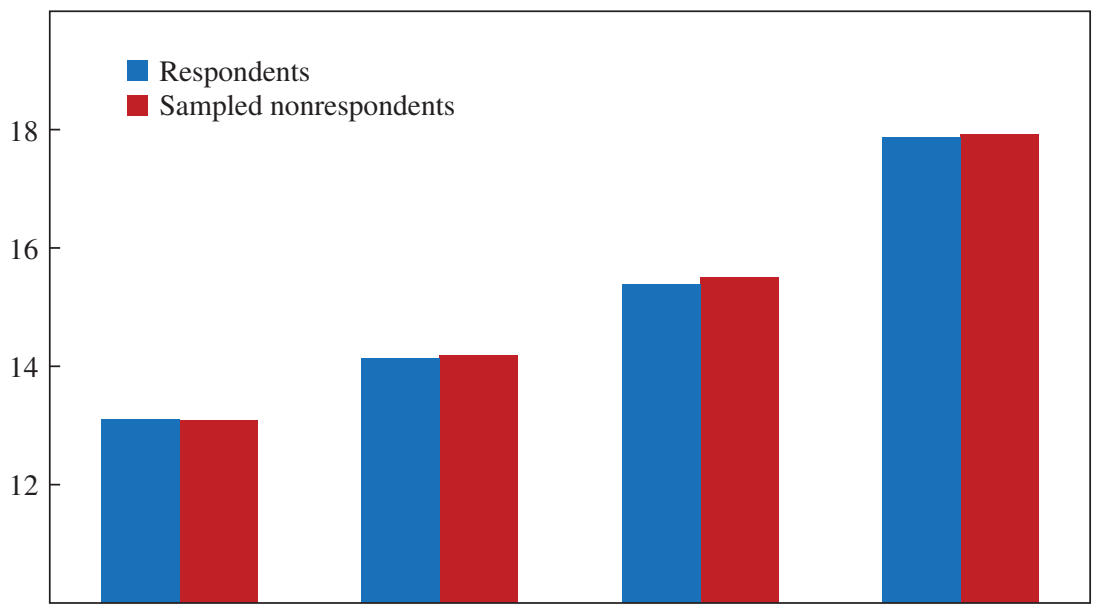

4th-highest stratum $\quad 3$ rd-highest stratum $\quad$ 2nd-highest stratum $\quad$ Highest stratum

\section{Capital income}

Log income

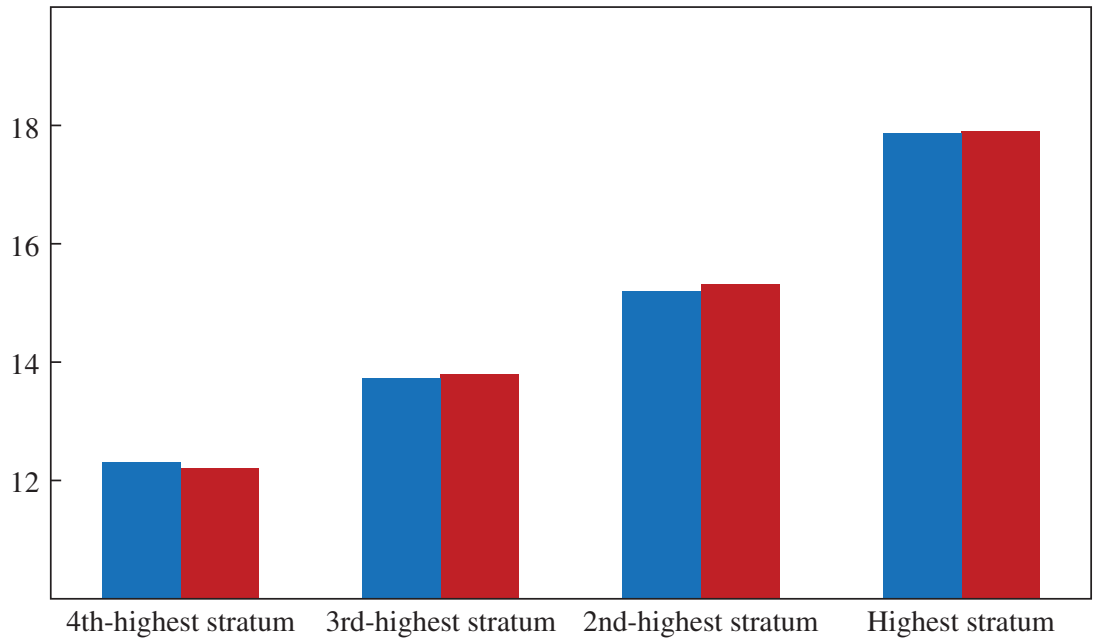

Sources: Internal Revenue Service, Statistics of Income Division, individual and sole proprietorship data. a. See the notes to figure 3 . 
Figure 5. Presurvey Income Volatility of the Top Strata of SCF Respondents and Nonrespondents, 2010-11

\section{Total income}

Percent of the top four strata

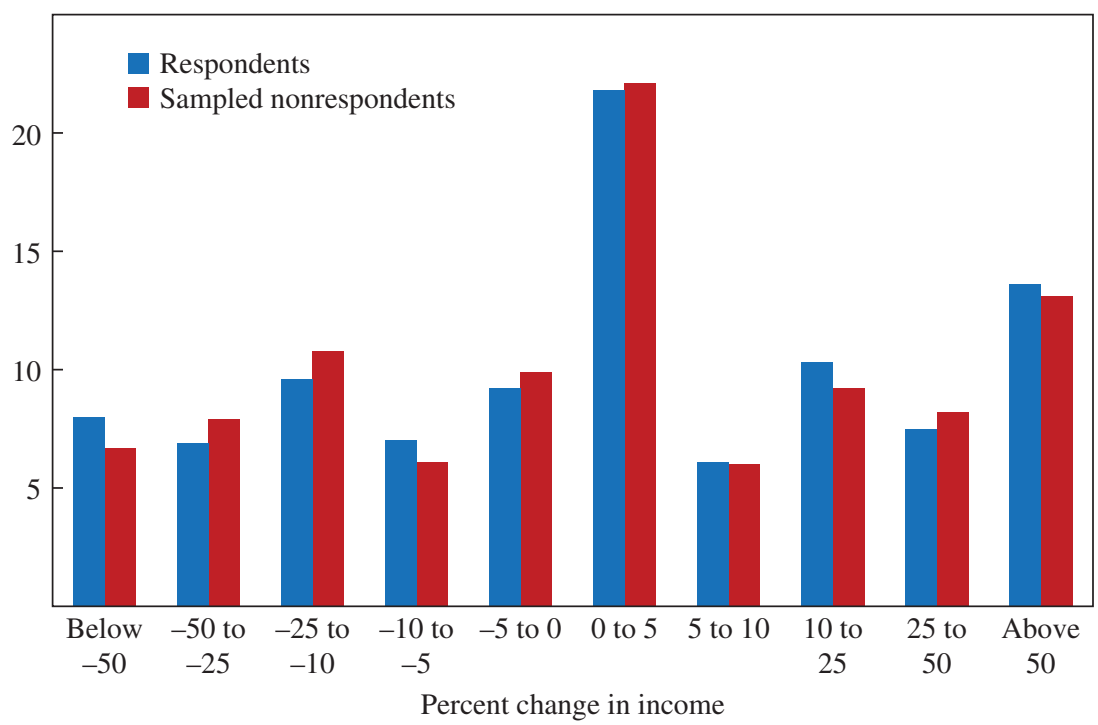

\section{Capital income}

Percent of the top four strata

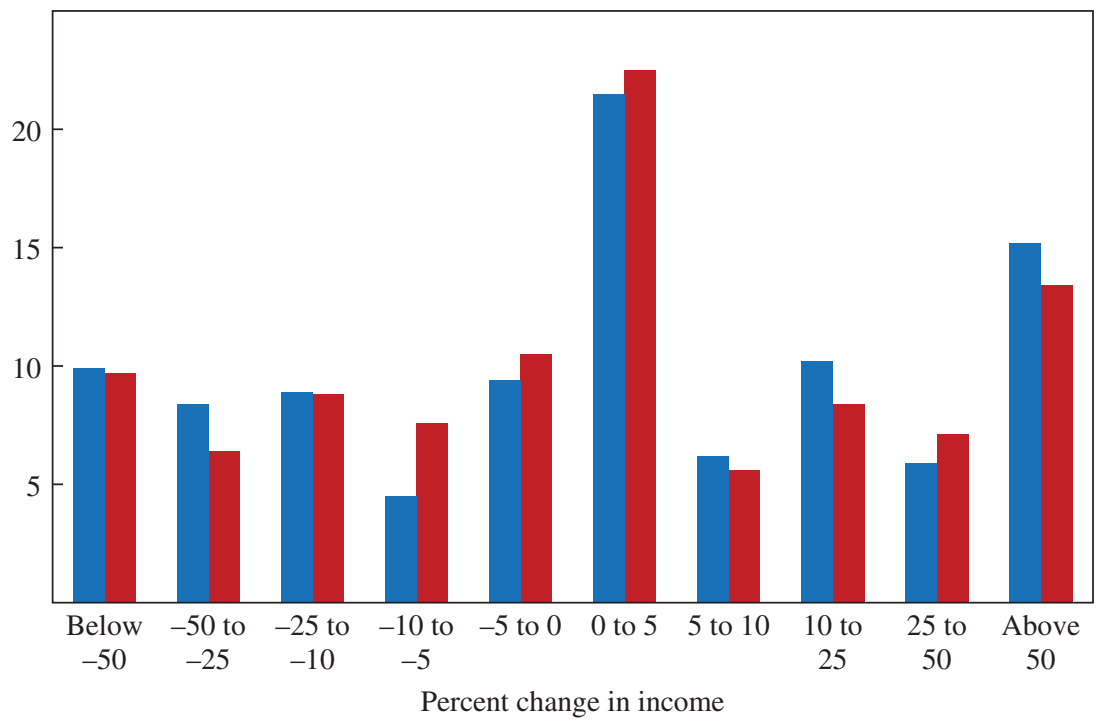

Sources: Internal Revenue Service, Statistics of Income Division, individual and sole proprietorship data. a. See the notes to figure 3 . 
Figure 6. Income Volatility of Families with an Adjusted Gross Income Greater Than $\$ 500,000,2011-12$

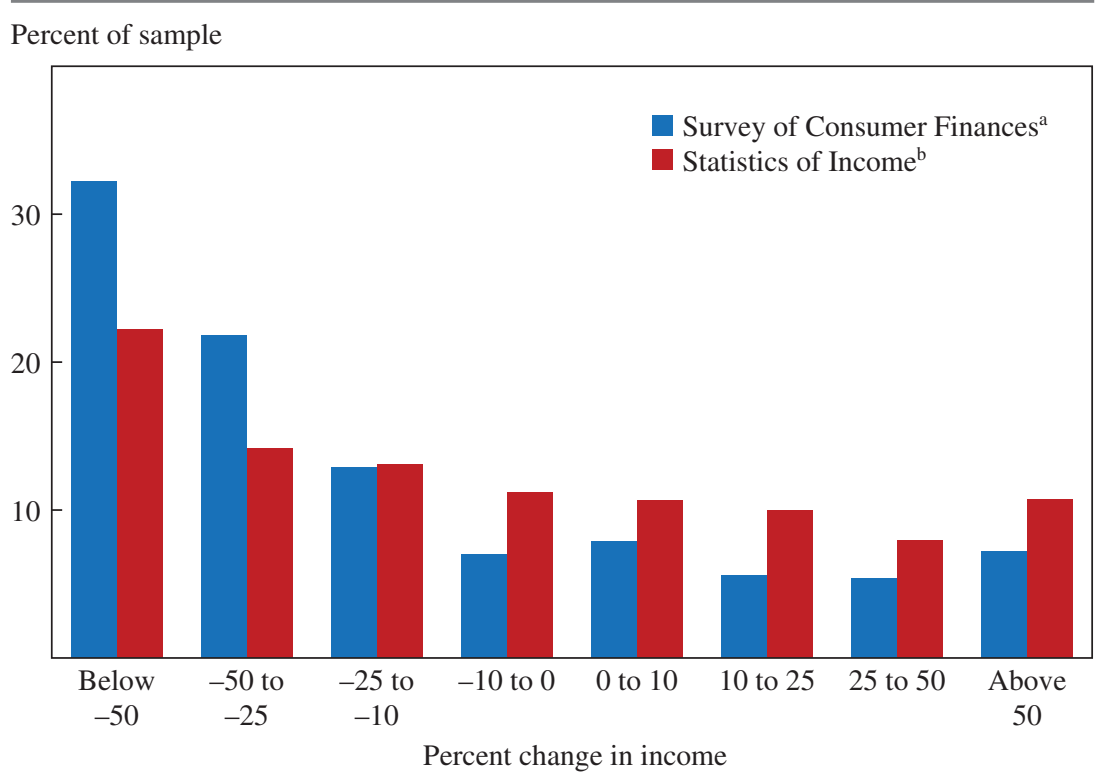

Sources: Survey of Consumer Finances; Internal Revenue Service, Statistics of Income Division, individual and sole proprietorship data (unpublished tabulations by Michael Parisi).

a. Shows the change in AGI from 2011 to 2012 among sampled SCF households with an AGI above $\$ 500,000$ in the individual and sole proprietorship data. The change in income is computed using the AGI provided by SOI in 2011, and the AGI is computed with the National Bureau of Economic Research's TAXSIM model using household income data from the 2013 SCF.

b. Shows the change in AGI from 2011 to 2012 among all tax returns with an AGI greater than $\$ 500,000$ in 2011.

High-income and high-wealth families typically have volatile incomes. For example, in the complete 2011 SOI data set, about 60 percent of the families with an adjusted gross income (AGI) greater than $\$ 500,000$ realized a decline in AGI in their 2012 tax filing (figure 6, right bars). At the tails, about 22 percent of the families in 2011 with an AGI greater than $\$ 500,000$ had a decline in income of 50 percent or more, and about 11 percent had an increase in income of 50 percent or more. However, of the 2011 SOI families with an AGI greater than $\$ 500,000$ that responded to the SCF, about 74 percent reported an annual income decline (survey-reported income relative to the last year of administrative sampling income), and nearly 32 percent reported a decline in income of 50 percent or more (figure 6 , left bars). Thus, although the patterns of income change in figure 6 are broadly similar, some high-income SCF respondents may be, on net, underreporting 2012 income, and the SCF data editing process does not correct for 
this underreporting. One possible explanation is that many high-income SCF families had not filed their taxes at the time of their interview, so they may have been unaware of their actual 2012 income during the interview. ${ }^{35}$

In addition to comparing growth rate distributions, it is possible to look at whether the SCF is capturing the very top of the SOI income distribution in any given year. One of the (now regular) tables published in the SOI Bulletin shows income thresholds for various top share groups, along with the amount of income earned above these thresholds. ${ }^{36}$ Thus, it is possible to look at various SOI cutoffs (for the top 10 percent, top 1 percent, and top 0.1 percent) and investigate whether the SCF finds the right number of families above these cutoffs, and the right amount of total income above the threshold. These comparisons are far from perfect, because the SCF is set up on a family basis while SOI is organized in tax units, and (although SCF respondents are asked to refer to their tax returns) the value of income they report may differ from the AGI concept in the SOI tables. ${ }^{37}$ Indeed, the modest biases one expects show up clearly: The SCF has more families above any given threshold and generally more income (additional family income will increase a given tax unit's income, which pushes a few more families over the threshold) except for the top 0.1 percent, for which the SCF finds roughly the same total income (the tax unit versus family distinction is less important as one gets closer to the very top). It is particularly important that we do not observe any trend in how well the SCF captures top incomes over time.

Though the SCF covers the top end of the income distribution, other comparisons of SCF and SOI incomes by source suggest that more general reporting challenges for capital income-such as interest, dividend, and business income-are likely affecting top families. For example, Barry

35. Almost 19 percent of SCF families in the top two sampling strata had not yet filed their taxes as of the interview date but planned to do so; only 4 percent of all other SCF families had not yet filed taxes. Many high-wealth families file their taxes late in the year, after getting an extension.

36. The archive of SOI Bulletins is available at https://www.irs.gov/uac/SOI-Tax-StatsSOI-Bulletins. For the most recent "Individual Tax Shares" report, see Dungan (2015). We are grateful to SOI for providing thresholds and counts in the early SCF years not covered in the published time series.

37. One subtle point about negative incomes affects the very top end in an important way. A taxpayer experiencing a capital loss may have that loss limited in a given tax year, but, for example, a business loss may be fully deductible against other positive incomes. Thus, if an SCF respondent accurately reports a loss, but misreports the type of loss, he could be misclassified based on "total" income. The analysis here is based on the SCF "total income" measure, which is, at the end of the day, the respondent's best estimate as to what he actually received during the year. 
Johnson and Kevin Moore (2008) show that aggregate total income in the SCF generally matches total aggregate income published by SOI, but the aggregates of some forms of capital income in the SCF appear to be understated, while wages and other types of income are overstated relative to the tax data. Saez and Zucman (2016) also state that the capital income concentration in the SCF is lower than the capital income concentration in the income tax data, and argue that this is evidence that the SCF is not capturing the top of the distribution.

How can the SCF capture the top of the income distribution and match total taxable income but have understated capital income shares? We argue that understated capital income in the SCF is mainly due to the classification of income. Wages as a share of the total income of the wealthiest SCF families has grown more than in the tax data since $2001 .{ }^{38}$ We concede that some of what respondents call "wages" may, in fact, be "business income," as the two could be thought of interchangeably by business owners. Business income is the largest source of capital income in both the SCF and the income tax data. ${ }^{39}$

The question posed at the beginning of this section is whether the SCF accomplishes its goal of identifying and surveying high-end families. The answer is basically yes, though given the restriction on auditing respondents, there will always be some uncertainty about exactly who is being included and whether their reported incomes are accurate. The importance of showing that the SCF captures families at the very top is, in one sense, a first-order point for our purposes here. But in another sense, it is just a corollary to the fact established later in the paper that, after being made conceptually equivalent, top wealth and income shares in the SCF and administrative tax data are effectively the same. Given that the populations in the two sets of micro data are effectively aligned, the more salient questions involve what we should be measuring conceptually, and how we should be measuring these desired concepts.

38. The wage share of income of the top 1 percent of SCF families was 47 percent in the 2001 SCF and was 49 percent in 2013 (authors' calculations). In the tax data, comparable wage share of families reporting more than $\$ 200,000$ in AGI (roughly comparable to the top 1 percent) was 45 percent and decreased to 44 percent (SOI table 1.4; see note 27).

39. We also show in the online appendix that the income tax data may be missing some forms of capital income for lower-income families in recent years, which would lend an upward bias to capital income concentration estimates in the income tax data in figures III and X of Saez and Zucman (2016). Further, the shares reported in the final year of these figures are undoubtedly biased up because 2012 was a year when many wealthy families chose to realize capital income (Wolfers 2015). 


\section{Top Wealth Shares in Administrative and Survey Data}

Wealth concentration has been at the center of recent media discussions (Feldstein 2015; Harwood 2015; Wolfers 2015) and academic discussions (Auerbach and Hassett 2015; Mankiw 2015; Piketty 2015; Weil 2015). In addition to concerns about the causes and effects of rising wealth concentration, some of the debate exists because different wealth concentration estimates paint contrasting pictures about what is actually happening. Published SCF household survey estimates indicate that wealth concentration at the top is high but increasing slowly (Bricker and others 2014), with a trajectory similar to that for estate tax data (Kopczuk and Saez 2004), though the level of wealth concentration is higher in the SCF. The inferences about top wealth shares using capitalized income tax data (Saez and Zucman 2016) indicate much higher and more rapidly growing wealth shares at the top of the wealth distribution, which has led to a substantial widening between levels of estimated wealth concentration in recent years.

In this section we present our preferred estimates of top wealth shares, and we show how these estimates compare with and contrast to both published SCF and gross capitalization estimates. Our preferred top share estimate is constructed by starting with the SCF wealth measures, adding the estimated wealth of the Forbes 400, and then distributing the value of DB pensions as measured in the FA. As described in section I.A, this preferred concept of wealth includes all assets (net of liabilities) over which a family has a legal claim that can be used to finance its present and future consumption.

We also investigate the source of divergence in growth rates and levels by constraining the SCF to conceptually match Saez and Zucman (2016). Using this approach, we are able to confirm that the differentials in wealth concentration are not attributable to the wealth concept per se, nor to population coverage or survey-reporting errors, and are, in fact, attributable to assumptions and methodology.

\section{II.A. Preferred Estimates of the Top Wealth Shares}

In all the estimates discussed here, the top wealth shares in the United States are very high and have been increasing over time. The top panel of figure 1 shows the estimated share of wealth owned by the top 1 percent for the period 1989-2013 based on three different measures, and the bottom panel of figure 1 shows the same for the top 0.1 percent wealth shares. In general, the estimated top wealth shares using the gross capitalization method applied to administrative tax data produced by Saez and Zucman 
(2016) are higher and have been growing more rapidly than the top wealth shares in published SCF estimates, and are also higher than those based on our preferred measure.

Our preferred measure of the top wealth shares begins with the published SCF Bulletin concept and estimates, next adds the wealth known to be missing because the Forbes 400 is excluded from the SCF sample, and then adds the value of DB pensions. ${ }^{40}$ With these two adjustments, the preferred measure is conceptually equivalent to household sector net worth in the FA, but excludes nonprofit institutions. ${ }^{41}$ Thus, the measure encompasses all the private resources available to families for present and future consumption. Most of this wealth is "marketable," in the sense of being available to trade for current consumption, with the exception of DB wealth, but this reflects private claims on future consumption.

The preferred measure shows slower growth in wealth concentration than in Saez and Zucman (2016). In fact, the preferred top shares' growth rate is very similar to the $\mathrm{SCF}^{42}$ Estimates of top wealth shares for both the top 1 percent and the top 0.1 percent were closer across the methods in the early years of the SCF than they are now, but differential growth rates have led to very different levels in recent years. In the most recent period, the preferred estimate of the top 1 percent wealth share is about 33 percent of total wealth, while the capitalized income value is nearly 42 percent. In a proportional sense, the divergence in the most recent years is even larger for the top 0.1 percent, with the preferred measure showing a share just under 15 percent of total wealth, and the capitalized income value more

40. "Bulletin" wealth derives its name from the fact that this is the consistent series published in the Federal Reserve Bulletin after each triennial survey. For the most recent survey, see Bricker and others (2014). Our estimate of Forbes 400 wealth is found by summing up the wealth of the families from the list, which was $\$ 2.021$ trillion in 2013 , or about 3 percent of total household wealth. We add this total to the total wealth in the SCF to create a new estimate of total U.S. family wealth. To compute a new top 1 percent estimate, we remove from the SCF top 1 percent those families that represent the 400 lowest-wealth families (weighted) and add the total Forbes 400 wealth, then divide by the new estimate of total U.S. family wealth (which includes Forbes 400 wealth). Alternatively, we can estimate the top shares after including the Forbes 400 families by using inferences from a Pareto distribution (Vermeulen 2014). The answers are qualitatively similar, though we prefer to use the data rather than make the inherent assumptions necessary for the Pareto distribution.

41. There are a few minor differences between the preferred measure and FA household sector net worth, described in the online appendix, and introduced to make the estimates more consistent with Saez and Zucman (2016). Primarily, we start with SCF Bulletin net worth, subtract vehicles, miscellaneous financial and nonfinancial assets, cash value of whole life insurance, and miscellaneous debt.

42. The slower growth of top shares in the SCF is also consistent with patterns in the top shares derived from estate tax data, as in Kopczuk and Saez (2004). Saez and Zucman (2016) include updates of the estate tax estimates, but these estimates are very sensitive to assumptions about mortality differentials for decedents affected by the estate tax. 
than 22 percent. The different measures all agree that wealth concentration is increasing within the top 1 percent, though the gross capitalization estimates are the most extreme in this regard.

\section{II.B. Reconciling the Wealth Concentration Estimates}

If the SCF sampling strategy does a good job capturing the top end of the wealth distribution, and SCF respondents do a good job reporting the values of their assets and liabilities, what is causing the substantial divergence between estimated top wealth shares in the SCF-based preferred and gross capitalization measures? Our approach to answering this question involves constraining the SCF to be conceptually and empirically similar to the gross capitalization estimates, and showing that most of the divergence is eliminated. In particular, when we measure top wealth shares after constraining SCF totals to match FA aggregates and adjusting the number of families in the top fractile to be consistent with tax unit counts, most of the recent level differences are eliminated, or at least are brought within the range of SCF statistical confidence.

The effects of constraining the SCF-based preferred top wealth share estimates to be conceptually and empirically equivalent to the gross capitalization estimates are shown in the top panel of figure 7 for the top 1 percent, and in the bottom panel of figure 7 for the top 0.1 percent. The first adjustment, which involves moving from the "Preferred" line to the "Preferred, FA concepts and values" line, is based on calibrating the sum of SCF values to match FA values across asset and liability categories. In general, the SCF and FA aggregates track very well over long periods of time. ${ }^{43}$ There are notable differences in levels and trends, however. Most important, the SCF finds a higher and (since 2001) more rapidly rising estimate for the value of owner-occupied housing, which has pushed up the ratio of SCF to FA net worth in recent years. ${ }^{44}$ Thus, when the SCF house values (and

43. See Dettling and others (2015) for a comparison of aggregate SCF and FA balance sheets for the 1989-2013 period. Also, Brown and others (2013) show that SCF debt by category generally tracks Equifax aggregates very well, though some categories such as credit cards are difficult to compare because of point-in-time versus revolving balance accounting for debt outstanding.

44. The differences in SCF and FA housing stock valuations are driven by the very different methodological approaches. In the aggregate FA data, the housing stock is valued using a perpetual inventory that involves new investment, depreciation, and a national house prices index. In the SCF, house values are owner-reported. Henriques and Hsu (2014) discuss how house values in the SCF compare favorably with other micro-based estimates, such as the American Housing Survey, and Henriques (2013) provides evidence that SCF respondents' house valuations generally track local area house price indexes quite well. See the online appendix for more details. 
Figure 7. Reconciling the Top Wealth Shares, 1989-2013

\section{Top 1 percent wealth shares}

Percent

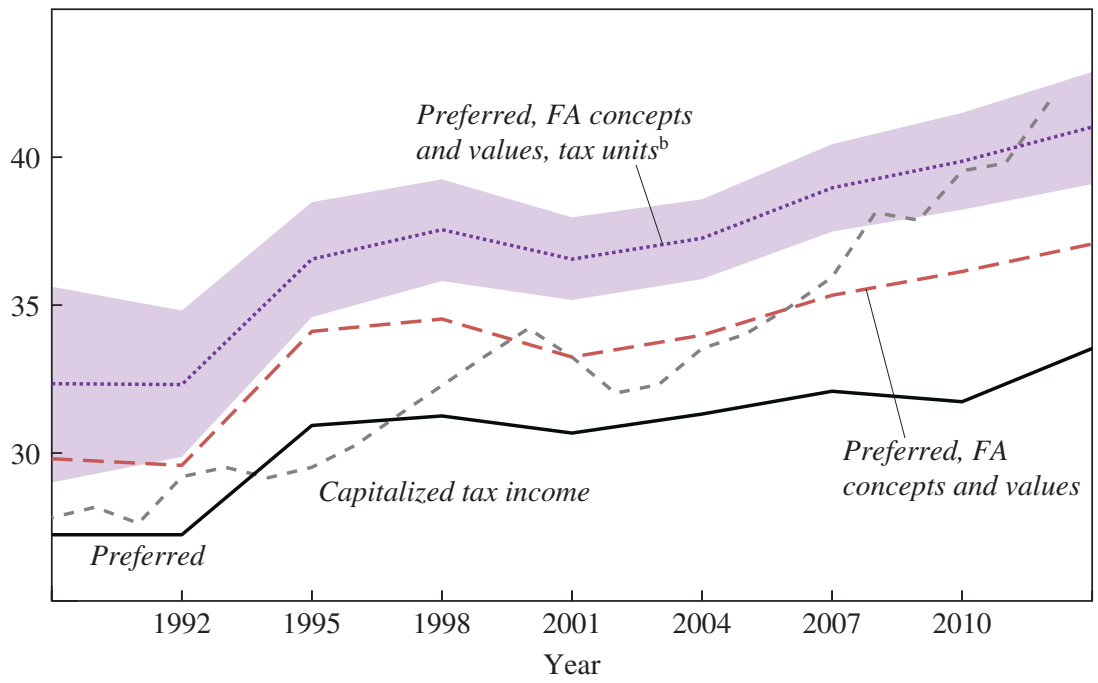

Top 0.1 percent wealth shares

Percent

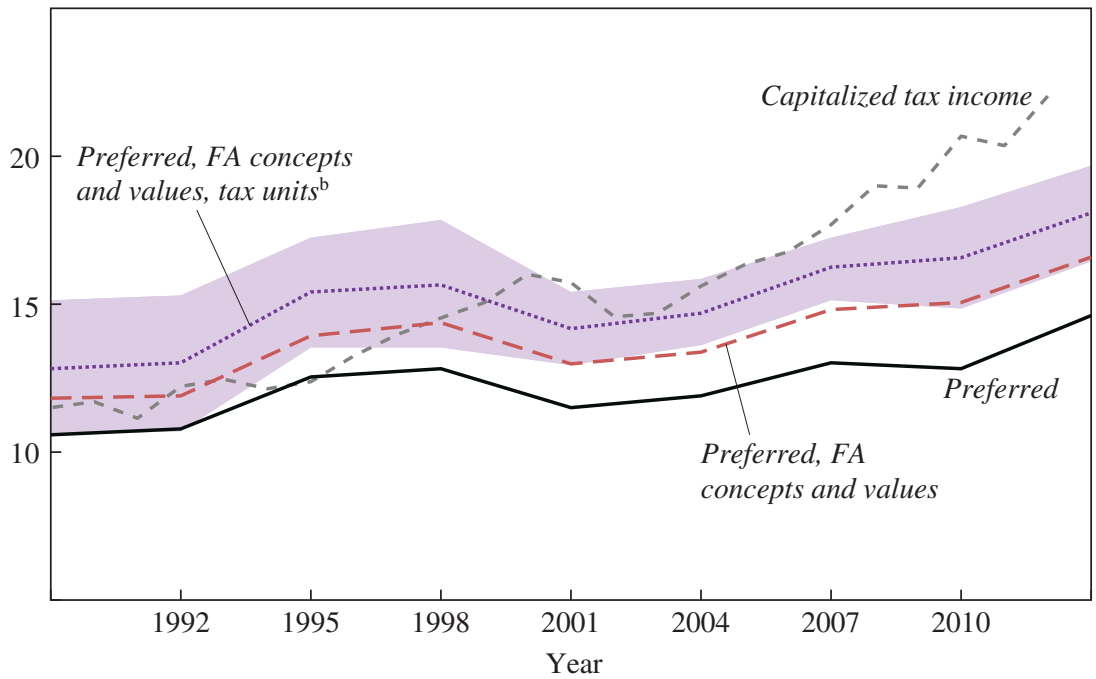

Sources: Survey of Consumer Finances; Saez and Zucman (2016).

a. See the text and the online appendix for more details on wealth concepts.

b. The shaded area represents the 95 percent confidence interval based on sampling and imputation variance. 
other asset and liability categories) are scaled to match the corresponding FA aggregates, owner-occupied housing is disproportionately scaled down. This differential rescaling is important, because the divergence in owneroccupied housing aggregates implies that benchmarking administrative data to FA instead of the SCF lowers wealth more below the top fractiles than above them, and more so for the top 0.1 percent than even the top 1 percent.

The second set of constraints imposed on the SCF adjustment involves shifting the top fractile cutoffs to be on a tax unit instead of a household basis..$^{45}$ The shift from the "Preferred, FA concepts and values" lines in both panels of figure 7 reflects the impact of imposing this constraint, and the lines labeled "Preferred, FA concepts and values, tax units" are again noticeably shifted up. We also add the shaded area around the second constrained top share estimates, which represents the 95 percent confidence interval. ${ }^{46}$ Indeed, all the differences in recent top 1 percent wealth shares are effectively eliminated when we constrain the SCF, and all but the most recent periods are reconciled for the top 0.1 percent. The exercise does raise questions about why, for example, the SCF top 1 percent wealth shares are above the capitalized values in the early years of the survey, and why the top 0.1 percent shares have been growing much more rapidly in recent years. But the magnitude of the adjustments and range of the confidence intervals makes it clear that top wealth shares are very sensitive to the specific data and methods being used.

\section{II.C. Gross Capitalization for Fixed-Interest Assets}

Much of the difference between our preferred estimates and the capitalized income top shares can be reconciled by trivial changes to the data, meaning whether or not to calibrate to the FA aggregates or whether to count the top 1 percent versus the top 1.3 percent of families. The remaining difference in top wealth shares is more about trends than levels, given that both the top 1 percent and top 0.1 percent wealth shares are rising more rapidly in the gross capitalization estimates, relative to even our constrained SCF-based estimates. It turns out that the gross capitalization

45. In practice, this constraint is imposed by simply changing the target counts of families in a given fractile to match the estimated number of tax units in a given fractile, which is the same as saying that every household at the top is also a tax unit. As noted earlier in the paper, there were about 30 percent more tax units than families in 2013, so one can think of the constrained "top 1 percent" as really representing the top 1.3 percent of families. The online appendix has details about the distributions of tax units versus families.

46. The online appendix and SCF website have details about how to use replicate weights and bootstrapping for generating confidence intervals consistent with the dual-frame sample design. 
implied rate of return on just one asset class (fixed income) is responsible for all the differential growth in wealth concentration at the very top. That is, when (more realistic) alternative rates of return are used in gross capitalization, the growth at the very top looks very much like the SCF-based top wealth share growth rates shown above.

The analysis of the biased gross capitalization factor begins with the actual (SCF) versus derived (gross capitalization) portfolios of the top 0.1 percent, as shown in figure 8 . Assets of the top wealth holders are broken down into four broad categories: housing, pensions, equity plus business, and fixed income. The shares of the first three are very similar, and the share of fixed-interest assets is also similar through 2001 or so. Indeed, all the differential growth in wealth of the top 0.1 percent occurs in the fixedinterest asset class, consisting mostly of bonds, certificates of deposit, call accounts, money market accounts, and other savings instruments. As of 2013, the gross capitalization approach implied that nearly half the assets owned by the top 0.1 percent were in the fixed-interest class.

Is this dramatic shift in portfolio composition plausible, or just an artifact of the gross capitalization approach implemented by Saez and Zucman (2016)? To answer this, we consider the implied gross capitalization factor underlying these estimates, and compare it with the implied capitalization factors if one instead uses a market rate of interest or an alternative based on estate tax filings. The result of these comparisons is shown in figure 9. The current low-interest-rate environment has led to increases in capitalization factors based on 10-year Treasury yields, the Moody's Aaa bond yield, or the ratio of prior year interest income to estate tax fixed-interest assets, any of which may be on the high end of plausible values. However, the implied gross capitalization factor solved for using the ratio of FA assets to administrative tax data interest income is much higher, and has clearly reached implausible levels. ${ }^{47}$ Based on this estimate, for every $\$ 1$ in observed interest income, gross capitalization is currently generating nearly $\$ 100$ in wealth. ${ }^{48}$

47. For reference, the gross capitalization model used in the SCF sampling exercise (see the online appendix) uses the Moody's Aaa rate to capitalize SOI interest income. It is also worth noting that the bond series in the B.101 table of the FA has been subject to downward revision as new source data have become available.

48. The rate of return on these sorts of assets does appear to vary across the wealth distribution in the SCF. In the $2013 \mathrm{SCF}$, the average rate of return on fixed-income assets (found by the ratio of SCF interest income to SCF fixed-income assets) across all households is about 1 percent, but the average rate of return for the top 1 percent of families is almost 6 percent. Fagereng and others (2016) also show that families at the upper tail of the wealth distribution have much higher rates of return than other families. 
Figure 8. Wealth Composition of the Top 0.1 Percent, Survey of Consumer Finances versus Capitalized Administrative Income Data, 1989-2013

\section{Survey of Consumer Finances}

Percent

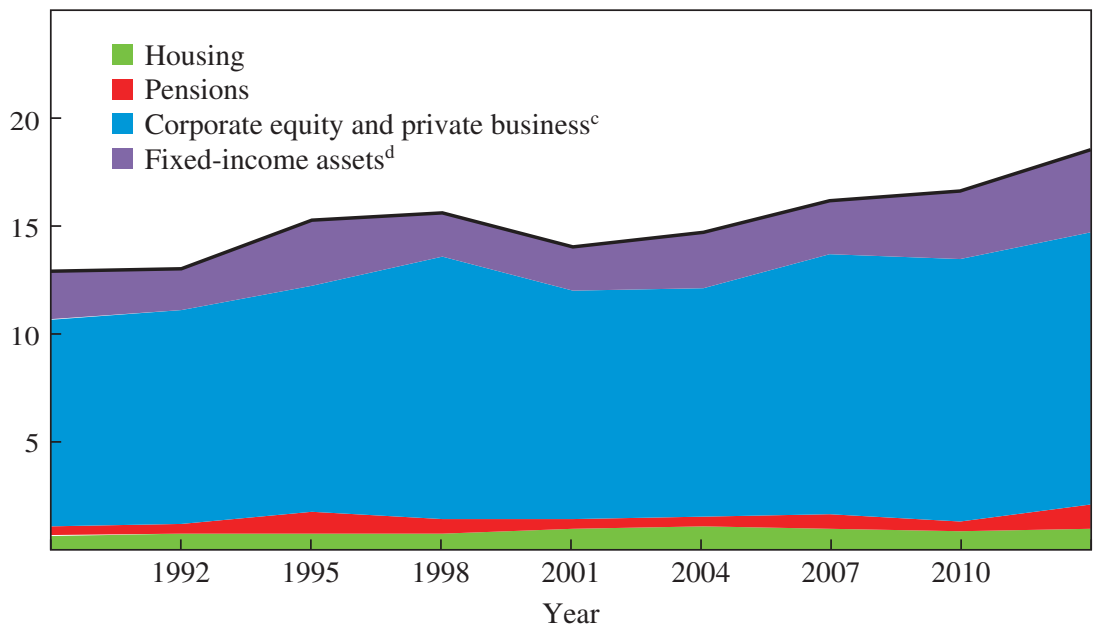

\section{Capitalized administrative income data $^{\mathrm{b}}$}

Percent

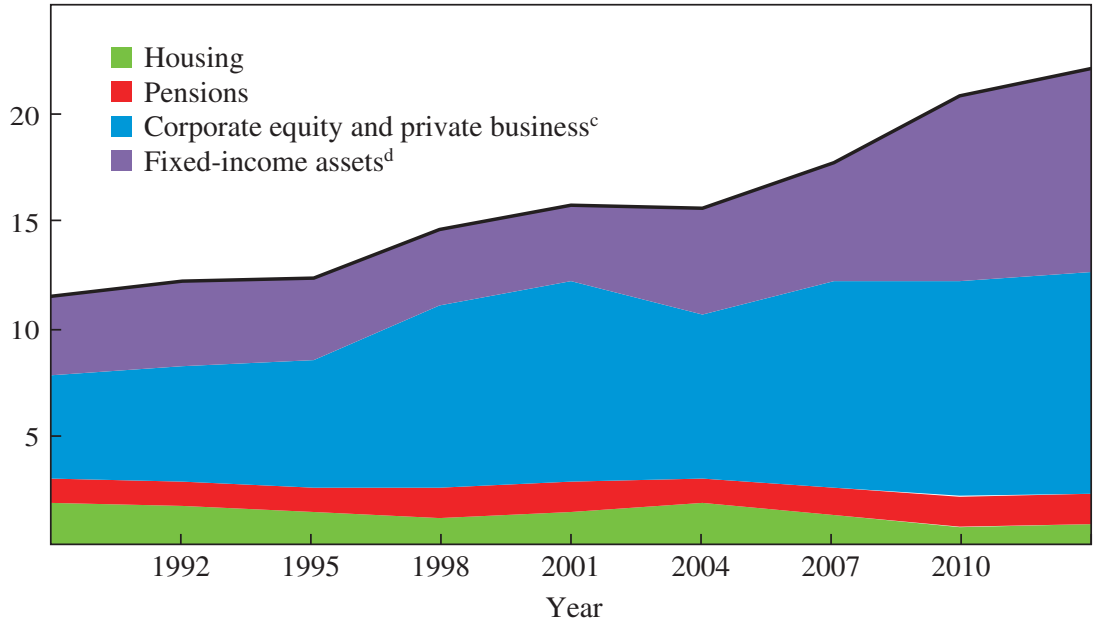

Sources: Survey of Consumer Finances; Saez and Zucman (2016).

a. The cumulative height of the figure is the SCF net worth benchmarked to FA values, adjusted for tax units, and including an estimate of the wealth of the Forbes 400. The assets of the Forbes 400, which are omitted from the SCF, are assumed to be split proportionally to the assets of the top 0.01 percent, according to Saez and Zucman (2016). The line at the top of the figure is equivalent to the line labeled "Preferred, FA concepts and values, tax units" in the bottom panel of figure 7.

b. Administrative data are through 2012, though labeled as 2013.

c. Includes the net worth of corporate equities, S corporations, partnerships, and sole proprietorships.

d. Includes bonds, certificates of deposit, savings accounts, and money market funds. 
Figure 9. Heterogeneity in the Capitalization Factors Used to Infer Fixed-Income Assets, 1989-2012

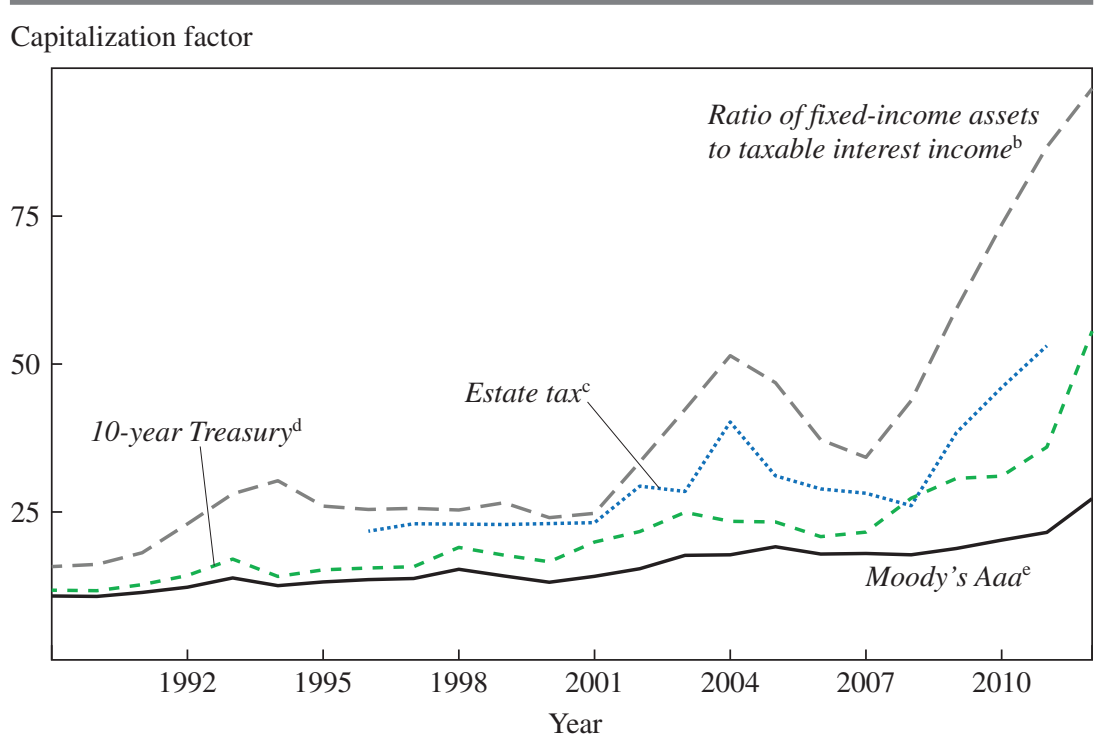

Sources: Moody's Investors Service; U.S. Department of the Treasury; Saez and Zucman (2016).

a. In a gross capitalization model, the capitalization factor for taxable interest income is the rate at which interest income will be grossed up to infer fixed-income assets.

b. Ratio of the stock of fixed-income assets in the FA to SOI taxable interest income.

c. Estimated rate of return on fixed income assets among a set of matched estate tax and income tax filers with more than \$20 million in estate tax assets from Saez and Zucman (2016).

d. Inverse of the annualized 10 -year Treasury yield.

e. Inverse of the annualized Moody's seasoned Aaa corporate bond yield.

Figure 10 makes the point clearly that there is basically no remaining unexplained difference in top 0.1 percent wealth shares when the constrained SCF is compared with gross capitalization when even a slightly more reasonable rate of return is used. Lowering the implied capitalization factor at the top to be consistent with (the still very conservative) 10 -year Treasury rate, the top 0.1 percent wealth share lies almost completely within the confidence interval for the constrained SCF estimates. The reestimated top 0.1 percent wealth share under the alternative gross capitalization parameters falls to just under 19 percent in the most recent period, which is still well above our preferred estimate of about 15 percent, but these differences are completely explained by the other constraints imposed above.

What is driving the implausible capitalization factors in the Saez and Zucman (2016) estimates? Our discussion of data and methods in section 
Figure 10. The Top Wealth Shares Using Alternative Capitalization Factors, 1989-2013

Percent

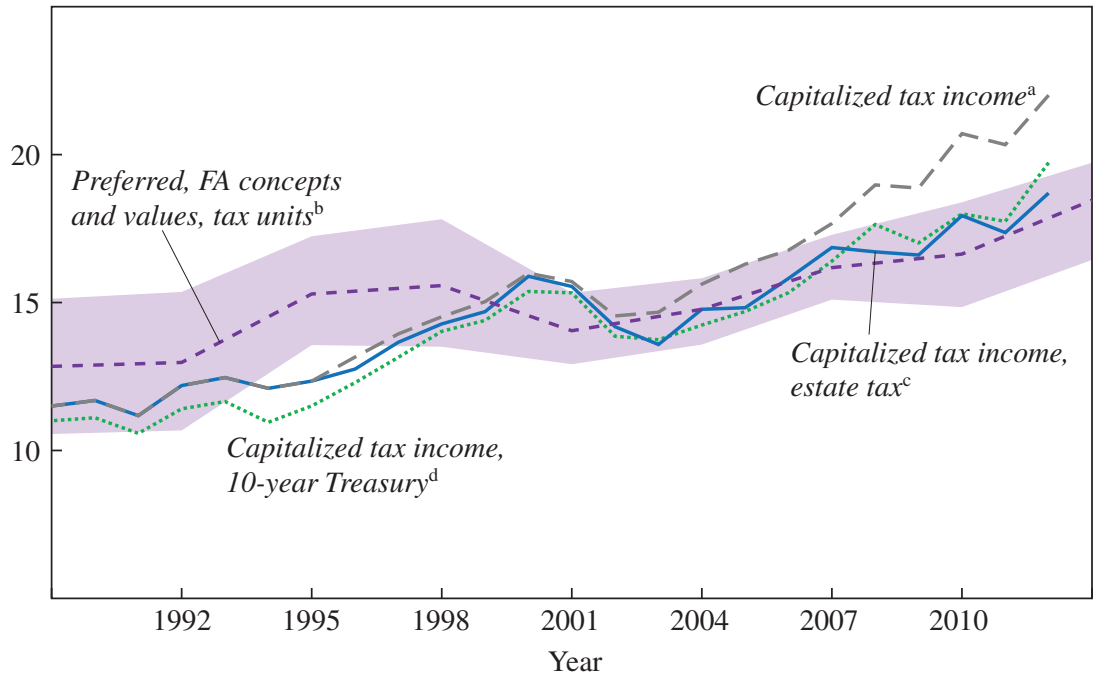

Sources: Survey of Consumer Finances; Saez and Zucman (2016).

a. Equivalent to the line labeled "Capitalized tax income" in the bottom panel of figure 7.

b. Equivalent to the line labeled "Preferred, FA concepts and values, tax units" in the bottom panel of figure 7. The shaded area represents the 95 percent confidence interval based on sampling and imputation variance.

c. Estimated top 0.1 percent wealth share when fixed income is capitalized based on the rate of return on fixed-income assets among estate tax filers with more than $\$ 20$ million in assets.

d. Fixed income assets for the top 1 percent of income earners are generated using the inverse of the 10-year Treasury yield, as in figure 9 . The fixed income assets for the bottom 99 percent of income earners are generated using the ratio of the stock of fixed-income assets in the FA to SOI taxable interest income, also as in figure 9.

I indicates that a few things can go awry when using the ratio of the estimated FA asset value to measured income flows. The FA asset totals include holdings by nonprofits, while the taxable income flow does not, so the gross capitalization factor is biased up. The household sector of the FA tries to separate out direct holdings from pension and other tax-preferred asset holdings, but any misclassification toward direct holdings will also bias up the numerator of the gross capitalization ratio. The household sector of the FA is also a residual claimant on asset holdings, so any sectoral misallocation of a given asset holding toward households will introduce bias. It is also likely that in the current low-interest environment, the much lower interest earnings on checking and savings deposits are going unmeasured in the tax data, and to the extent that these are more relevant for families outside the top 1 percent, their share of fixed-interest assets is being 
allocated to the top wealth families that have (quantitatively observable) interest. Ultimately, however, given the available data, we cannot point to any one explanation with certainty. ${ }^{49}$

\section{Top Income Shares in Administrative and Survey Data}

Income concentration and wealth concentration are both contentious issues, and many see the two measures as strongly correlated. Everyone seems to know that the rich are getting richer, whether we categorize them as rich by their income or their wealth. In some ways income concentration is a more straightforward measure, because we can look directly at administrative data to gauge how the top income shares are evolving over time, rather than (as in gross capitalization for wealth shares) requiring additional assumptions about the relationship between income and the value of the assets that are generating this income. However, in another sense, the concept of income itself has changed in fairly dramatic ways during the period when top income shares have been rising, and we will show that these conceptual changes are having a first-order impact on estimated top shares.

In this section we present our preferred estimates of the top income shares, and, as with the top wealth shares, we show how these preferred estimates compare with and contrast to both the published SCF and the administrative tax-based estimates. Our preferred top income share estimate is constructed by starting with SCF income measures, then adding components of NIPA personal income that are not measured in the SCF. The preferred measure shows slower growth in income concentration than the estimates by Piketty and Saez (2003), based on administrative tax data; but unlike the top wealth shares, our preferred top income shares are also (modestly) lower and have been rising more slowly than published SCF estimates. We investigate the source of divergence in top income growth rates and levels by once again constraining the SCF to conceptually match the administrative tax-based estimates. Using this approach, we are able to confirm that the differentials in income concentration are not (at least on a first approximation) attributable to a lack of population coverage at the very top or to survey underreporting in the SCF.

49. Some of these issues may impart serious bias to the capitalization factors. The online appendix describes these issues in more detail, and some back-of-the-envelope calculations suggest that substantial biases in capitalization factors are likely introduced by these inconsistencies between micro income and macro balance sheet estimates. 


\section{III.A. Preferred Estimates of the Top Income Shares}

In all the estimates discussed here, the top income shares in the United States are high and have been increasing over time. The top panel of figure 2 shows the estimated share of income received by the top 1 percent for the period 1988-2012 based on three different measures, and the bottom panel of figure 2 shows the same for the top 0.1 percent income shares. In general, the estimated top income shares based on administrative tax data from Piketty and Saez (2003) are higher and have been rising more rapidly than the top income shares in published SCF estimates, and are also higher than those based on our preferred measure.

The differences between the various estimated top income shares are, as with wealth shares, first-order. For 2012, our preferred estimate of the top 1 percent income share is just under 18 percent, while the administrative tax-based estimate is nearly 23 percent. The gap is proportionally larger for the top 0.1 percent, and both gaps have been increasing over time, though, as with wealth, much of the increase in the top 1 percent income share can be accounted for by the top 0.1 percent income share. That is, the substantial income gains are occurring within the top 1 percent and not just for the 1 percent as a whole.

Our preferred measure for top income shares begins with the published SCF Bulletin concept and estimates. As with top wealth shares, the first adjustment on the income side is needed because the Forbes 400 is excluded from the SCF sample. Although the Forbes 400 account for about 3 percent of total household sector net worth, the relationship between income and wealth is such that the Forbes 400 account for a much smaller fraction of income, and thus adding them generally increases the average incomes of the top groups by a more modest amount. ${ }^{50}$ Thus, the estimated shares of income received by the top income groups are pushed up, but the effects are much more muted than for the top wealth shares.

The more substantial adjustments are to the SCF income concepts, and involve adding the in-kind transfers included in NIPA PI but not measured

50. The Forbes 400 is based on estimated wealth holdings, and Forbes makes no attempt to produce estimates of the incomes those families earn during the year. We estimate their incomes using information on income and wealth for the top 0.1 percent of families in the SCF sample, for which we know both income and wealth. For those top families, we compute the median ratio of income to wealth, and then we apply that ratio to the estimated Forbes 400 wealth. Although the Forbes 400 account for about 3 percent of total wealth, our approach suggests they account for less than 1 percent of income. 
in the SCF survey. In particular, we add the value of employer-provided health insurance; the value of in-kind government transfers such as SNAP; and the value of Medicaid, Medicare, and other government health care programs. Together, these incomes amounted to about 7 percent of NIPA PI in 1988, but had roughly doubled as a share of PI by 2012. This increasing share of total PI interacts with the casual observation that these forms of income are much less concentrated than the measured incomes, and this pulls down the preferred top shares every year, but disproportionally more in recent years. ${ }^{51}$ This is seen most clearly in the gaps between the published SCF income measure and our preferred measure; the modest but rising Forbes 400 income share is pulling the two together, but the addition of in-kind incomes is larger and, on net, pushing the two apart.

\section{III.B. Reconciling the Income Concentration Estimates}

We approach the reconciliation of the income shares from the same basic starting point as we used for wealth shares. If the SCF sampling strategy does a good job capturing the top end of the income distribution and SCF respondents do a good job reporting their incomes, what is causing the substantial divergence between the estimated top income shares in the SCF-based preferred and administrative tax-based measures? Again, we constrain the SCF to be conceptually and empirically similar to the taxbased measures, and we show that most of the divergence is eliminated. In particular, when we measure the top income shares after constraining the SCF income concept to match the tax-based concept and we adjust the number of families in the top fractile to be consistent with the tax unit counts, most of the level differences are eliminated, or are at least brought within the range of SCF statistical confidence.

The effects of constraining the SCF-based preferred top income share estimates to be conceptually and empirically equivalent to the administrative tax-based estimates are shown in the top panel of figure 11 for the top 1 percent, and in the bottom panel of figure 11 for the top 0.1 percent. The first adjustment, which involves moving from the "Preferred" line to the "Market income, families" line, is based on restricting the SCF income concept to match what is available in the tax data (see table 2). This basically involves removing cash transfers-most notably Social Security

51. The distribution of the in-kind transfers is, as with our wealth imputations, driven by the available data in the SCF. Employer-provided health care benefits are distributed across families based on their reported employer-sponsored health care coverage, Medicare is distributed equally for eligible families, and the means-tested transfers are all distributed to the bottom 99 percent by income. 
Figure 11. Reconciling the Top Income Shares, 1988-2012

\section{Top 1 percent income shares}

Percent

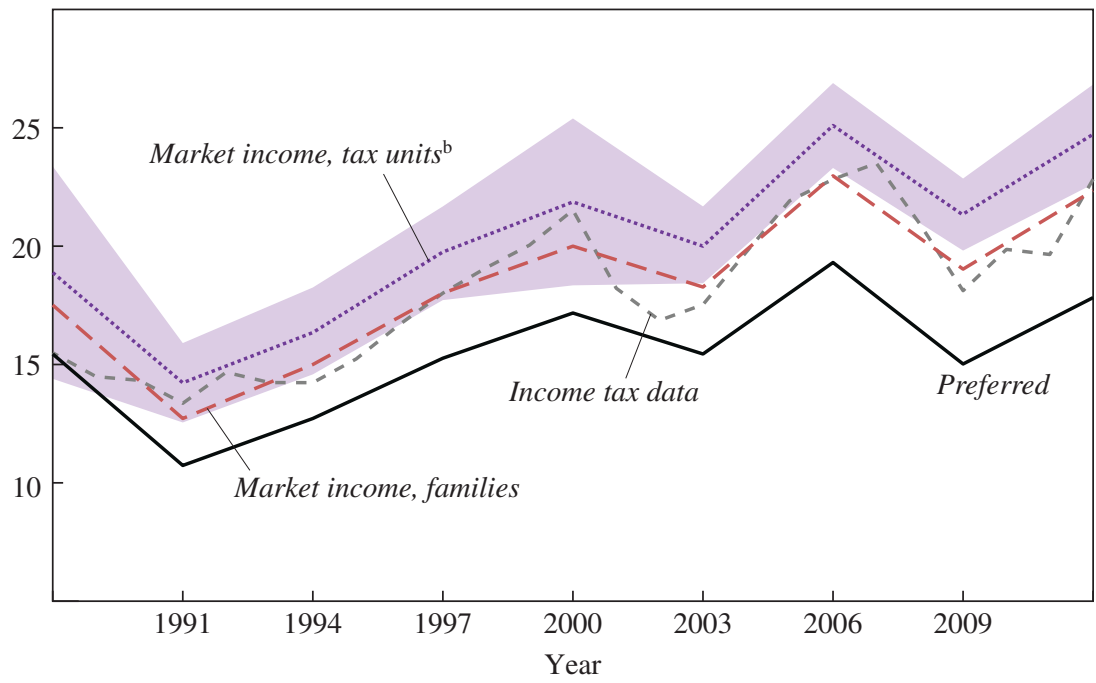

Top 0.1 percent income shares

Percent

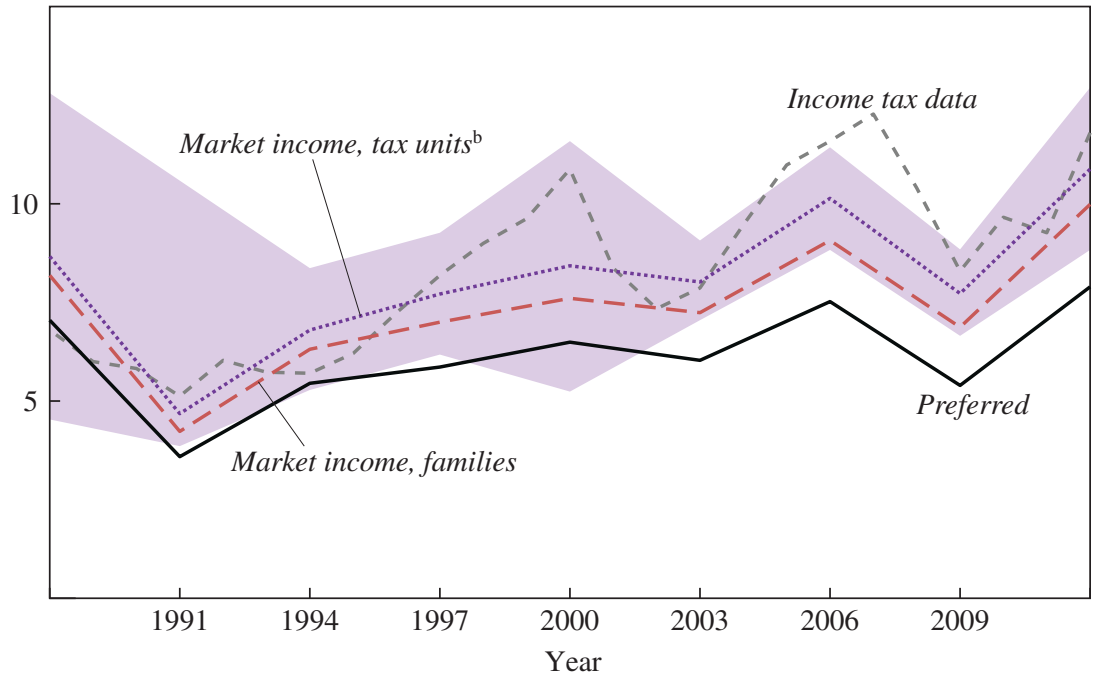

Sources: Survey of Consumer Finances; Piketty and Saez (2003).

a. SCF incomes are collected for the calendar year preceding each triennial survey. See the text and the online appendix for more details on income concepts.

b. The shaded area represents the 95 percent confidence interval based on sampling and imputation variance. 
benefits, but also other cash transfers-from the SCF income concept. Because these forms of income are disproportionately received by families in the bottom 99 percent by income, removing these forms shifts the concentration numbers up. And because these forms are becoming increasingly important, their effects have been larger in recent years. The quantitative effect of moving from the SCF Bulletin income measure to the more restrictive market income measure is to move the income concentration estimates further away from the preferred income measure, and for the same reasons.

The second reconciliation, as with the wealth shares, also uses the constrained market income concept, and further involves redefining how many families the top fractiles represent. Again, there are 30 percent more tax units than families in 2012, and thus the top 1 percent on a tax unit basis represents about 1.6 million families instead of the 1.2 million families in the top 1 percent using the SCF and preferred distributional measures. Adding the extra 400,000 families to the top 1 percent, and the extra 40,000 families to the top 0.1 percent, increases the top share estimates in a predictable and sizable way, the lines labeled "Market income, tax units." The remaining differences between the top income shares in the constrained SCF and administrative tax data are mostly about volatility, and not levels per se. Further, the width of the confidence intervals shows how income variability and sampling interact, especially at the very top, to generate a wide confidence interval for estimated top shares. ${ }^{52}$ Indeed, the point estimates for the constrained SCF top 1 percent income shares are actually above the administrative tax-based estimates, and are basically the same for the top 0.1 percent.

\section{III.C. Even More Comprehensive Incomes?}

The steps taken to reconcile our preferred top income shares with the administrative tax-based estimates are suggestive of a broader question. What else is missing from an even more comprehensive income measure, and what might be the result of incorporating these other missing pieces into the analysis of top income shares? Figure 12 reinforces the fact that the more comprehensive income measures in our preferred top income

52. The working paper version of this paper (Bricker and others 2015) has more details on the variability of top incomes, particularly with respect to the capital income shares. Saez and Zucman (2016) emphasize that the failure of the SCF to capture top capital incomes is indicative that the survey is missing the top wealth holders, but we show there that most of the capital income at the top is captured as well after doing the same reconciliation exercise we do here for total incomes, and the remaining modest differences are likely associated with some of the reporting issues discussed in section I of this paper. 
Figure 12. Aggregate Income Measures as a Percent of the Aggregate NIPA Measure, 1970-2012

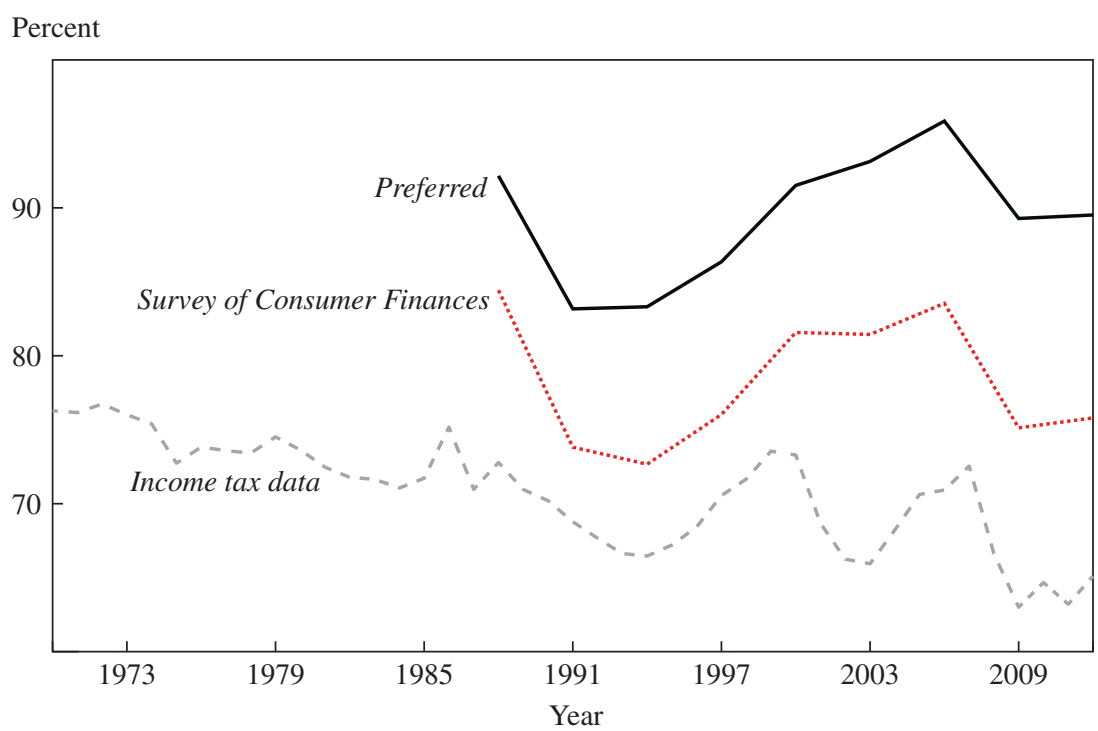

Sources: Survey of Consumer Finances; U.S. Bureau of Economic Analysis; Piketty and Saez (2003).

shares diverge from the narrow administrative tax-based measures and the SCF Bulletin measure, and that even our preferred measure is not complete. Even though the three income measures in the micro data all include something the PI measure does not—realized capital gains_-even our most comprehensive income estimate is still less than the NIPA total.

The remaining divergence between NIPA PI and our preferred income measure involves a mix of imputations, known and unknown underreporting, and unreconciled conceptual discrepancies. It might be feasible in principle to produce distributional estimates for incomes, such as imputed rent on owner-occupied housing or the value of in-kind financial services, using a data set like the SCF. One could also imagine rescaling the SCF-reported incomes in categories for known underreporting for, say, a proprietor's income, but this underreporting is also known to have a distributional component (small proprietors are worse when it comes to underreporting) that would need to be considered. Some adjustments of tax basis versus economic profit and rent have also been incorporated into the NIPA, and one would need to work through them in order to align the comprehensive PI measure. Although these various adjustments might affect the 
estimated top shares, it is not clear in what direction. What is clear is that further adjustments such as these should be done very carefully, and that simply scaling the available data to match the aggregates could bias the final answer.

\section{Concluding Remarks}

Rising top wealth and income shares are often cited as a call to action by those who believe that government can and should do more about inequality vis-à-vis taxation, spending, regulation, and other market interventions. Rising inequality raises obvious normative concerns, and there is a growing belief that recent macroeconomic instability and slow growth may be additional symptoms of the same underlying phenomenon. ${ }^{53}$ Economists disagree about the fundamental causes of rising inequality, as some argue that the trends are associated with free market prices adjusting to equate supply and demand, while at the other extreme some argue that the influence wielded by those who are already wealthy improves their market shares by changing the rules of the game. ${ }^{54}$

The preferred estimates for the top wealth and income shares presented here reflect what we think can be gleaned from the best available data sources, including administrative tax data, the SCF, and macro aggregates. The estimates agree with the widely held view that inequality, at least as reflected in the top wealth and income shares, has been rising in recent decades. However, the levels and trends in our preferred top share estimates are more muted than those in recent studies that are based directly on administrative income tax data (Piketty and Saez 2003; Saez and Zucman 2016), but the levels and trends for the top wealth shares are a bit larger than the estimates based on estate tax data (Kopczuk and Saez 2004).

Although the SCF makes it possible to inform and improve on direct estimates of the top wealth and income shares derived from administrative tax data, the survey is still far from capturing comprehensive wealth and income measures. The SCF adds some government transfers to the taxoriented income measures, but it still misses employer-provided benefits, government in-kind (especially health care) transfers, and other forms of

53. For a somewhat contrary position on the economic stability effects, see Bordo and Meissner (2012).

54. The view that markets underlie rising inequality is well described by Kaplan and Rauh (2010, 2013). See also Jones (2015) for a discussion of how competition among innovators affects the top shares. 
income that are both substantial and growing over time. There are also direct analogs in shortcomings in the wealth measures; for example, the value of most families' key retirement asset-Social Security—is not measured as part of household net worth. ${ }^{55}$ The effect of these omissions is important for understanding the top shares, and even more important when looking at inequality across the entire distribution.

The reconciliations made here cannot be extended back in time before the development of the modern SCF household survey, but the specific issues raised draw attention to how changes in government policies and market practices are affecting the measurement of top shares over time. In particular, although the administrative tax data make it possible to show that the top share families are getting increasingly large slices of a particular pie, the pie's overall size being measured in these data is shrinking relative to more economically meaningful concepts of wealth and income. The increasingly unmeasured part of the pie is not disappearing, but it is evolving. It may be difficult or even impossible to allocate the missing pieces in the very long historical series; thus, any very long-term trends should also be viewed with an eye toward the conceptual divergence being driven by evolving government policy and economic institutions.

Building on the theme of conceptual measurement, the reconciliation of top shares presented here speaks directly to the underlying impetus forand possible approaches to- public policy toward wealth and income distribution. The failure to properly measure the effects of government policies and market practices that disproportionately benefit families in the middle and bottom of the wealth or income distribution leads directly to an overstatement of the top wealth and income shares. Policies and practices such as social insurance and government investment in human capital generate real benefits, and the debate is thus properly focused on the distribution of these benefits. If we measure only the costs of such policies and practices, without measuring the benefits, it becomes more difficult to make the case in favor of such policies in debates.

55. The Social Security actuaries estimate that the present value of future Social Security benefits for current workers is currently about $\$ 58$ trillion, which is nearly the size of conventionally measured household sector net worth. Social Security wealth is also rising faster than other forms of wealth. Devlin-Foltz, Henriques, and Sabelhaus (2016) show how the distribution of Social Security wealth for near-retirees interacts with other forms of retirement wealth. Not surprisingly, given the progressive nature and cap on earnings in the benefit formula, Social Security wealth is disproportionately important for the bottom half of the wealth distribution. 
ACKNOWLEDGMENTS We would like to thank our colleagues on the Survey of Consumer Finances project who made this research possible: Lisa Dettling, Sebastian Devlin-Foltz, Joanne Hsu, Kevin B. Moore, Sarah Pack, Jeffrey P. Thompson, and Richard Windle. For input and comments on this and earlier versions of this paper, we also thank our editor, James Stock; and our discussants, Katharine Abraham and Wojciech Kopczuk; as well as Mariacristina De Nardi, Diana Hancock, Arthur Kennickell, José-Víctor RíosRull, Emmanuel Saez, Gabriel Zucman, and the seminar participants at the Brookings Panel on Economic Activity, the Federal Reserve Board, the Bank of England, the Bank of Spain, and the Household Finance and Consumption Network's meeting at the European Central Bank. Jesse Bricker thanks Olympia Bover and the Bank of Spain for hospitality at the early stages of this work. Finally, we are grateful to Michael Parisi for providing unpublished tabulations of Statistics of Income data, and to Barry W. Johnson and the Statistics of Income staff for contributions to the Survey of Consumer Finances sample design. The analysis and conclusions set forth in this paper are those of the authors alone, and do not indicate concurrence by other members of the research staff or the Board of Governors of the Federal Reserve System. 


\section{References}

Armour, Philip, Richard V. Burkhauser, and Jeff Larrimore. 2014. "Levels and Trends in U.S. Income and Its Distribution: A Crosswalk from Market Income towards a Comprehensive Haig-Simons Income Approach." Southern Economic Journal 81, no. 2: 271-93.

Atkinson, Anthony B., Thomas Piketty, and Emmanuel Saez. 2011. “Top Incomes in the Long Run of History." Journal of Economic Literature 49, no. 1: 3-71.

Attanasio, Orazio, Erik Hurst, and Luigi Pistaferri. 2015. "The Evolution of Income, Consumption, and Leisure Inequality in the United States, 1980 2010." In Improving the Measurement of Consumer Expenditures, edited by Christopher D. Carroll, Thomas Crossley, and John Sabelhaus. University of Chicago Press.

Auerbach, Alan J., and Kevin Hassett. 2015. "Capital Taxation in the Twenty-First Century." American Economic Review 105, no. 5: 38-42.

Bordo, Michael D., and Christopher M. Meissner. 2012. "Does Inequality Lead to a Financial Crisis?" Working Paper no. 17896. Cambridge, Mass.: National Bureau of Economic Research.

Bricker, Jesse, Lisa J. Dettling, Alice Henriques, Joanne W. Hsu, Kevin B. Moore, John Sabelhaus, Jeffrey Thompson, and Richard A. Windle. 2014. "Changes in U.S. Family Finances from 2010 to 2013: Evidence from the Survey of Consumer Finances." Federal Reserve Bulletin 100, no. 4.

Bricker, Jesse, Alice Henriques, Jacob Krimmel, and John Sabelhaus. 2015. "Measuring Income and Wealth at the Top Using Administrative and Survey Data." Finance and Economics Discussion Series, no. 2015-030. Washington: Board of Governors of the Federal Reserve System.

Brown, Meta, Andrew Haughwout, Donghoon Lee, and Wilbert van der Klaauw. 2013. "Do We Know What We Owe? A Comparison of Borrower- and LenderReported Consumer Debt." Staff Report no. 523. Federal Reserve Bank of New York.

Burkhauser, Richard V., Shuaizhang Feng, Stephen P. Jenkins, and Jeff Larrimore. 2012. "Recent Trends in Top Income Shares in the United States: Reconciling Estimates from March CPS and IRS Tax Return Data." Review of Economics and Statistics 94, no. 2: 371-88.

Burkhauser, Richard V., Jeff Larrimore, and Kosali I. Simon. 2012. "A 'Second Opinion' on the Economic Health of the American Middle Class." National Tax Journal 65, no. 1: 7-32.

Congressional Budget Office. 2014. "The Distribution of Household Income and Federal Taxes, 2011." Washington. https://www.cbo.gov/publication/49440

Debacker, Jason, Bradley Heim, Vasia Panousi, Shanthi Ramnath, and Ivan Vidangos. 2013. "Rising Inequality: Transitory or Persistent? New Evidence from a Panel of U.S. Tax Returns." Brookings Papers on Economic Activity, Spring: 67-122.

Dettling, Lisa J., Sebastian J. Devlin-Foltz, Jacob Krimmel, Sarah J. Pack, and Jeffrey P. Thompson. 2015. "Comparing Micro and Macro Sources for Household 
Accounts in the United States: Evidence from the Survey of Consumer Finances." Finance and Economics Discussion Series, no. 2015-086. Washington: Board of Governors of the Federal Reserve System.

Devlin-Foltz, Sebastian, Alice M. Henriques, and John Sabelhaus. 2016. "Is the U.S. Retirement System Contributing to Rising Wealth Inequality?" Russell Sage Foundation Journal of the Social Sciences, forthcoming.

Dungan, Adrian. 2015. "Individual Income Tax Shares, 2012." Statistics of Income Bulletin (Internal Revenue Service, Statistics of Income Division), Spring.

Fagereng, Andreas, Luigi Guiso, Davide Malacrino, and Luigi Pistaferri. 2016. "Heterogeneity in Returns to Wealth and the Measurement of Wealth Inequality." American Economic Review 106, no. 5: 651-55.

Feldstein, Martin. 2015. "The Uncounted Trillions in the Inequality Debate." Wall Street Journal, December 13.

Greenwood, Daphne. 1983. "An Estimation of U.S. Family Wealth and Its Distribution from Microdata, 1973." Review of Income and Wealth 29, no. 1: 23-44.

Guvenen, Fatih, Greg Kaplan, and Jae Song. 2014. "How Risky Are Recessions for Top Earners?” American Economic Review 104, no. 5: 148-53.

Harwood, John. 2015. "10 Questions with Bernie Sanders.” CNBC, May 26. www. cnbc.com/2015/05/26/10-questions-with-bernie-sanders.html

Henriques, Alice M. 2013. "Are Homeowners in Denial about Their House Values? Comparing Owner Perceptions with Transaction-Based Indexes.” Finance and Economics Discussion Series, no. 2013-79. Washington: Board of Governors of the Federal Reserve System.

Henriques, Alice M., and Joanne W. Hsu. 2014. "Analysis of Wealth Using Microand Macrodata: A Comparison of the Survey of Consumer Finances and Flow of Funds Accounts." In Measuring Economic Sustainability and Progress, edited by Dale W. Jorgenson, J. Steven Landefeld, and Paul Schreyer. University of Chicago Press.

Johnson, Barry W., and Kevin Moore. 2008. "Differences in Income Estimates Derived from Survey and Tax Data." In Proceedings of the Joint Statistical Meetings, Survey Research Methods Section. Alexandria: American Statistical Association.

Jones, Charles I. 2015. "Pareto and Piketty: The Macroeconomics of Top Income and Wealth Inequality.” Journal of Economic Perspectives 29, no. 1: 29-46.

Kaplan, Steven N., and Joshua Rauh. 2010. "Wall Street and Main Street: What Contributes to the Rise in the Highest Incomes?" Review of Financial Studies 23, no. 3: 1004-50.

—. 2013. "It's the Market: The Broad-Based Rise in the Return to Top Talent." Journal of Economic Perspectives 27, no. 3: 35-56.

Kennickell, Arthur B., and R. Louise Woodburn. 1999. "Consistent Weight Design for the 1989, 1992, and 1995 SCFs, and the Distribution of Wealth." Review of Income and Wealth 45, no. 2: 193-215.

Kopczuk, Wojciech. 2015a. "Recent Evolution of Income and Wealth Inequality: Comments on Piketty's Capital in the Twenty-First Century." Tax Law Review 68, no. 3: 545-62. 
2015b. "What Do We Know about the Evolution of Top Wealth Shares in the United States?" Journal of Economic Perspectives 29, no. 1: 47-66.

Kopczuk, Wojciech, and Emmanuel Saez. 2004. "Top Wealth Shares in the United States, 1916-2000: Evidence from Estate Tax Returns." National Tax Journal 57, no. 2: 445-87.

Kuznets, Simon. 1953. Shares of Upper Income Groups in Income and Savings. New York: National Bureau of Economic Research.

Mankiw, N. Gregory. 2015. "Yes, $r>$ g. So What?" American Economic Review 105, no. 5: 43-47.

McKeever, Brice S. 2015. "The Nonprofit Sector in Brief 2015: Public Charities, Giving, and Volunteering.” Washington: Urban Institute, Center on Nonprofits and Philanthropy.

O’Muircheartaigh, Colm, Stephanie Eckman, and Charlene Weiss. 2002. "Traditional and Enhanced Field Listing for Probability Sampling." In Proceedings of the Joint Statistical Meetings, Survey Research Methods Section. Alexandria: American Statistical Association.

Pareto, Vilfredo. 1896. Cours d'Économie Politique. Geneva: Droz.

Parker, Jonathan A., and Annette Vissing-Jorgensen. 2010. "The Increase in Income Cyclicality of High-Income Households and Its Relation to the Rise in Top Income Shares.” Brookings Papers on Economic Activity, Fall: 1-55.

Piketty, Thomas. 2014. Capital in the Twenty-First Century. Belknap Press. . 2015. "About Capital in the Twenty-First Century." American Economic Review 105, no. 5: 48-53.

Piketty, Thomas, and Emmanuel Saez. 2003. "Income Inequality in the United States, 1913-1998." Quarterly Journal of Economics 118, no. 1: 1-39.

Rajan, Raghuram G. 2010. Fault Lines: How Hidden Fractures Still Threaten the World Economy. Princeton University Press.

Sabelhaus, John, David Johnson, Stephen Ash, David Swanson, Thesia I. Garner, John Greenlees, and Steve Henderson. 2015. "Is the Consumer Expenditure Survey Representative by Income?" In Improving the Measurement of Consumer Expenditures, edited by Christopher D. Carroll, Thomas Crossley, and John Sabelhaus. University of Chicago Press.

Saez, Emmanuel, and Gabriel Zucman. 2016. "Wealth Inequality in the United States since 1913: Evidence from Capitalized Income Tax Data." Quarterly Journal of Economics 131, no. 2: 519-78.

Smeeding, Timothy M., and Jeffrey P. Thompson. 2011. "Recent Trends in Income Inequality: Labor, Wealth and More Complete Measures of Income." In Who Loses in the Downturn? Economic Crisis, Employment and Income Distribution, edited by Herwig Immervoll, Andreas Peichl, and Konstantinos Tatsiramos. Bingley, U.K.: Emerald Group.

Stiglitz, Joseph E. 2012. The Price of Inequality: How Today's Divided Society Endangers Our Future. New York: W. W. Norton.

Vermeulen, Philip. 2014. "How Fat Is the Top Tail of the Wealth Distribution?" Working Paper no. 1692. European Central Bank. 
Weil, David N. 2015. "Capital and Wealth in the Twenty-First Century." American Economic Review 105, no. 5: 34-37.

Wolfers, Justin. 2015. "The Gains from the Economic Recovery Are Still Limited to the Top One Percent." New York Times, January 28.

Yellen, Janet L. 2014. "Perspectives on Inequality and Opportunity from the Survey of Consumer Finances." Speech given at the Conference on Economic Opportunity and Inequality, Federal Reserve Bank of Boston, Boston, October 17. 


\section{Comments and Discussion}

\section{COMMENT BY}

KATHARINE G. ABRAHAM Evidence that income and wealth have become increasingly concentrated in recent years-more specifically, evidence that a growing share of income and wealth is controlled by households in the top 1 percent or top 0.1 percent of these distributions-has attracted enormous scholarly and popular attention. Although there is general agreement that both income and wealth have indeed become more concentrated, different data sources tell somewhat different stories about the magnitude of these changes. Most notably, estimates of the share of wealth controlled by households at the very top of the distribution based on income tax records (Saez and Zucman 2016) show much larger recent growth than estimates based on data from the Survey of Consumer Finances (SCF).

This very useful paper by Jesse Bricker, Alice Henriques, Jacob Krimmel, and John Sabelhaus does two main things. First, it carefully reconciles the competing estimates of growth in the concentration of income and wealth based on different data sources. It has persuaded me that the true growth in the concentration of wealth in recent years has been considerably smaller than suggested by the widely cited estimates reported by Emmanuel Saez and Gabriel Zucman (2016). Second, the paper offers a preferred set of estimates of the top 1 percent and top 0.1 percent shares of income and wealth that are neither the SCF estimates nor the tax data-based estimates. Mainly because I am skeptical about the choice of concepts for constructing the preferred estimates, I find this part of the paper less compelling. Absent from the paper is any discussion of who has lost as those at the top of the distributions of income and wealth have gained, a point to which I return below.

RECONCILING ESTIMATES OF INCOME AND WEALTH CONCENTRATION The paper looks at a great deal of evidence in the course of evaluating potential biases 
in alternative estimates of the top 1 percent and top 0.1 percent shares of income and wealth. In working through the discussion of this evidence and trying to keep it all straight, I found myself thinking that the total survey error framework familiar to my survey methodology colleagues might have provided a useful way to organize the information presented.

From a total survey error perspective, two types of things can go wrong with a survey estimate (Groves and others 2009). First, the surveyed units might do a poor job of representing the population of interest. This could be due to (i) problems with the coverage of the survey sampling frame (coverage error), (ii) the unavoidable variability that arises when information is collected only from a subset of the units of interest (sampling error), (iii) problems that arise because the units that respond differ in some important respect from those that do not (nonresponse error), or (iv) problems related to any postsurvey adjustments made to the survey weights (adjustment error). Second, the information collected from survey units might not capture what the survey designer actually hoped to learn about. This could be due to (i) the specified measure not corresponding adequately to the construct of interest (concept validity), (ii) problems with the accuracy of the responses provided in answer to the questions posed (measurement error), or (iii) problems with the processing of the responses obtained (processing error).

Representation issues. Although the total survey error frameworkwith its categorization of potential problems as being related to either representation or measurement-was originally developed for thinking about survey estimates, and though some of the specific issues it identifies are less applicable outside the survey context, it can easily be adapted to the evaluation of estimates based on administrative or other nonsurvey data. Within this framework, the fact that, by design, the SCF does not capture the 400 or so very wealthiest U.S. households can be classified as a representation issue. In the paper's preferred estimates, the income and wealth known to be missing because the top 400 families are excluded from the SCF sample is added back before the top 1 percent and top 0.1 percent shares are calculated.

Given the very low response rate in the SCF for wealthy households more generally, a more interesting question is whether, aside from the top 400 households, the SCF adequately represents the well-to-do. The paper makes a convincing case that households in the higher-wealth SCF strata that provide usable responses to the survey are quite similar to those that do not respond. The analysis reported in the paper gives me a good deal of confidence that, once the SCF data have been reweighted to account for 
differential nonresponse rates across strata, they should do a reasonably good job of representing all but the 400 wealthiest households.

The representation issue for the tax data lies at the opposite end of the distribution, with low-income households that do not file a tax return and therefore are missing from the data. Estimates based on tax data must be adjusted to account for the absence of these households, but seemingly adequate methods have been developed for doing this.

A related issue concerns the unit of accounting used to produce the SCF and tax data-based estimates. The SCF produces estimates for families, whereas estimates based on tax data pertain to tax-filing units. One new fact I learned from the paper is that high-income families are less likely than low-income families to file multiple tax returns, meaning that the top 1 percent (or top 0.1 percent) of families account for a materially smaller share of income and wealth than the corresponding share of tax-filing units. This discrepancy is fairly uniform across years, however, meaning that the choice of reporting unit does not explain the different trends in the tax data-based and SCF estimates of the concentration of wealth.

Measurement issues. The measurement side of the total survey error framework begins with the concepts that are adopted. For the purpose of measuring the share of income received by those at the top of the income distribution, the paper adopts as its benchmark the definition of personal income in the National Income and Product Accounts (NIPA). This consists of market income derived from current production plus current transfer receipts less current social insurance contributions. The paper's preferred wealth concept is a market measure, consisting of the value of household financial and nonfinancial assets plus rights to defined-benefit pensions, less the value of household liabilities.

Neither the tax data-based income measure nor the SCF income measure corresponds exactly to the NIPA's personal income concept; nor do they correspond exactly to one another. All three income concepts include most market income, though there are some differences across them related to the treatment of capital gains and of retirement income. The more significant differences across the three income measures have to do with how transfers are treated. The concept underlying the tax data-based estimates completely excludes transfers. The SCF concept includes cash transfers from Social Security, Supplemental Security Income, Temporary Assistance for Needy Families, and other transfer programs. Because cash transfers are more important at the lower end of the income distribution, their inclusion lowers the estimated top 1 percent and top 0.1 percent shares of income in the SCF estimates relative to the tax data-based estimates, 
though the trends in the two sets of estimates are not too different. The even lower level of the authors' preferred top income share estimates is largely attributable to both cash and in-kind transfers being treated as income.

The concepts underlying the tax data-based and SCF estimates of wealth concentration are more similar, though the SCF estimates miss definedbenefit pension wealth and the tax data-based estimates miss nonmortgage debt. The key factor, however, for understanding why estimates of the top wealth shares based on the two sources have trended so differently turns out to be how the data—and especially the tax data—are processed. For the most part, the SCF data measure the value of asset holdings directly. In the tax data, wealth holdings are estimated as the capitalized value of observed income flows. The basic idea is that, given the amount of investment income of a particular type and information about the rate of return on assets of that type, the value of the underlying assets can be inferred. More specifically, the implied value of a household's holdings of fixedincome assets would be calculated as the income realized on these holdings times $1 / r$, where $r$ is an appropriate interest rate. The ratio $1 / r$ would be referred to as the capitalization factor for the fixed-income asset category.

In the analysis by Saez and Zucman (2016), the capitalization factor for inferring the value of fixed-income assets from the associated flow of interest payments is set equal to the ratio of the aggregate value of fixed-income assets, as recorded in the Financial Accounts of the United States, to aggregate interest income from tax data. In recent years, the capitalization factor implied by these calculations has grown to be very large—by 2012, each $\$ 1$ in reported interest income translated into nearly $\$ 100$ in implied asset holdings. The resulting increase in the implied value of the fixed-income assets held by the wealthiest taxpayers accounts for most of the growth in the top 1 percent and top 0.1 percent shares of overall wealth as estimated by Saez and Zucman (2016).

Although the approach just described is logical, the results are potentially very sensitive to errors in the calculated interest rate that determines the capitalization factor. Bricker, Henriques, Krimmel, and Sabelhaus show that applying capitalization factors based on any of a set of market interest rates produces much different answers than those obtained by Saez and Zucman (2016), with each \$1 in interest income in 2012 (the most recent year for which Saez and Zucman report) translating into about $\$ 25$ to $\$ 50$, rather than nearly $\$ 100$, in implied asset holdings.

One potential contributor to Saez and Zucman's (2016) capitalization factor having grown too large that was identified by Bricker and his col- 
leagues is that, in the recent environment of very low interest rates, a significant share of interest-bearing accounts have not generated the minimum $\$ 10$ in interest payments that triggers the issuance of Form 1099-INT. To the extent that interest payments for which no 1099-INT is generated are not reported on recipients' tax returns, total interest income will be understated, leading to a corresponding overstatement in the capitalization factor and the holdings of fixed-income assets by high-income taxpayers. Perhaps surprisingly, the back-of-the-envelope calculations done by Bricker and his colleagues (shown in the online appendix to their paper) suggest that this factor alone could have caused Saez and Zucman's (2016) capitalization factor to be overstated by as much as 25 percent.

Although the paper does not fully explain the reasons for the difference between Saez and Zucman's (2016) capitalization factors for fixed-income assets and the capitalization factors based on market interest rates, I am convinced that Saez and Zucman's (2016) calculations significantly overstate the recent growth in the top 1 percent and top 0.1 percent shares of market wealth. Rather than having grown dramatically from about 28 percent in 1992 to about 42 percent in 2013, as implied by calculations based on income tax data using the methods developed by Saez and Zucman (2016), the authors' preferred estimate is that the top 1 percent share of wealth has grown by considerably less, from about 27 percent in 1992 to about 33 percent in 2013. The effect of the different methods on the estimated growth in the top 0.1 percent share of market wealth is, if anything, more marked. I view this as the paper's most important finding.

CONSTRUCTING PREFERRED ESTIMATES OF INCOME AND WEALTH CONCENTRATION Let me turn now to the paper's second objective: the production of preferred estimates of the top 1 percent and top 0.1 percent shares of income and wealth that are neither the SCF estimates nor the tax data-based estimates. A number of decisions have been made regarding the production of these estimates, including decisions about both what should be measured and how the measures should be constructed. In deciding what should be measured, Bricker and his colleagues are guided by the concepts that underlie the measure of personal income in the NIPA and the measure of market wealth contained in the U.S. Financial Accounts. One question I have about these choices is whether the treatment of taxes and transfers in the preferred measures makes good sense, given the likely reasons for data users to be interested in them. A further issue is the adoption of an annual observation window for measuring the concentration of income among those at the top of the income distribution. 
The treatment of taxes and transfers. As with the estimates based on tax data and the SCF estimates, the preferred estimates of the top 1 percent and top 0.1 percent shares of income proposed in the paper are constructed on a pretax basis. The tax data-based income concept excludes transfer income altogether, and the SCF income concept adds cash transfers but not in-kind transfers. The more encompassing preferred income concept, which corresponds more closely to the NIPA personal income concept, incorporates both cash and in-kind transfers. A key point here is that the preferred income estimates are pretax but posttransfer, a conceptual formulation that from the perspective of thinking about the distribution of income seems to me to be rather betwixt and between. Measures of the concentration of market income convey information about the distribution of the returns to market activity. Measures of the concentration of income based on a posttax and posttransfer income concept, which would map to the NIPA disposable personal income concept, convey information about the ultimate distribution of control over resources after societally determined redistributions have been made. It is less clear to me, however, how to think about the hybrid pretax and posttransfer concept that is adopted for the calculation of the paper's preferred income concentration measures.

With respect to measuring the concentration of wealth, the tax databased estimates, the SCF estimates, and the preferred estimates all rest on a market wealth concept that generally corresponds to the concept used for the measurement of wealth in the U.S. Financial Accounts. Though sensible in isolation, making this choice for the preferred wealth measure introduces an inconsistency between the preferred income concept, which includes the value of both cash and in-kind transfers rather than being purely market based, and the preferred wealth concept, which includes only market wealth. As already noted, I am not entirely comfortable with the pretax and posttransfer concept underlying the preferred measures of income concentration. That said, I also am not entirely comfortable with the income concept and the wealth concept being defined on different bases. On this point, I would note that, with respect to thinking about household wellbeing, the expected present values of Social Security and Medicare benefits are the largest "assets" that many households possess (Steuerle and Quakenbush 2015). In a very real sense, ignoring the anticipated value of these transfers provides a misleading picture of the resources available to lower- and middle-income households. Defined more comparably to the preferred measures of income concentration, the estimated concentration of wealth in the hands of the top 1 percent or top 0.1 percent of households would look less extreme. 
An annual frame of reference. A second potentially important issue about the preferred income estimates that I would like to flag is the adoption of an annual frame of reference for the calculation of measures of income concentration. Although this is entirely standard in the literature, I have reservations about whether such a measure in fact tells us what we really want to know. When a layperson thinks about the concentration of income, my guess would be that he or she has in mind something more akin to a measure of the concentration of income averaged over some period of years.

As noted in the paper, there is considerable idiosyncratic year-to-year volatility in incomes, especially at the very top of the income distribution. This is illustrated in my figure 1, constructed using data from the paper's figure 6 , kindly supplied by the authors. The numbers plotted in the figure come from unpublished tabulations of tax data prepared by the Statistics of Income Division at the Internal Revenue Service. The figure shows, for the sample of tax-filing units with an adjusted gross income of more than $\$ 500,000$ in 2011 , the share of units experiencing various percentage decreases or percentage increases in adjusted gross income between 2011 and 2012. It is clear that the incomes of such households can change

Figure 1. Percent Change in Income for Tax-Filing Units with Adjusted Gross Income Greater than $\$ 500,000,2011-12$

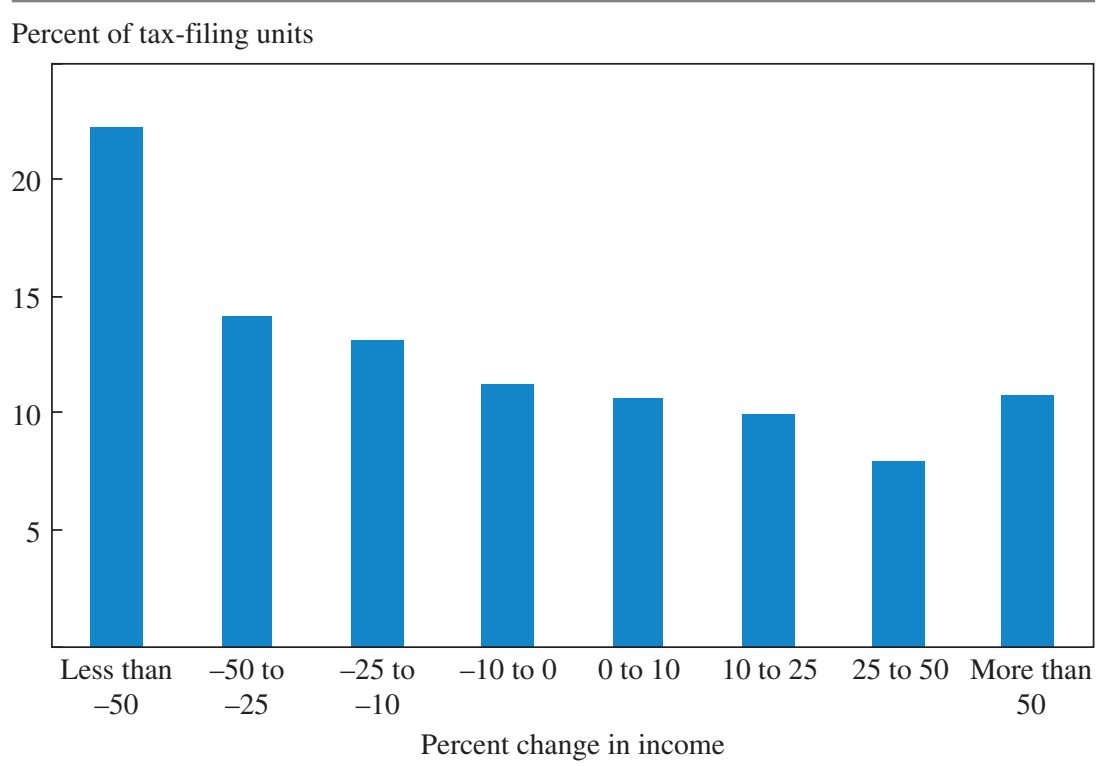

Source: Internal Revenue Service, Statistics of Income Division (unpublished tabulations). 
dramatically from one year to the next. More than half of those with annual incomes in excess of $\$ 500,000$ in 2011 experienced a drop or an increase in income of more than 25 percent the following year.

Because the peaks and valleys will tend to average out over time, household income averaged over several years will tend to be less concentrated than household income in any single year. This same phenomenon can be seen clearly in related research on the inequality of earnings that has compared estimated inequality based on annual earnings with earnings averaged over several years (Kopczuk, Saez, and Song 2010). Further, changes in the volatility of income over time could impart a trend to measured annual income concentration relative to the concentration of income averaged over several years, though it is an empirical question as to whether this has been important in practice. In any case, it would be good to know whether and to what extent conclusions with respect to recent trends in the inequality of income are robust to the use of multiyear rather than singleyear income data.

LOOKING BEYOND THE VERY TOP My final comment about the paper pertains to its exclusive focus on the shares of income and wealth among those at the very top of the distributions - the shares of income and wealth controlled by the top 1 percent or top 0.1 percent of households. It is undoubtedly of interest to know whether and by how much the shares of income and wealth controlled by these groups have changed. That said, I also would very much like to know at whose expense these gains are coming. My feeling about gains at the very top will be quite different to the extent that they are coming at the expense of households in the 90th through 98th percentiles rather than at the expense of households in the bottom 20 percent or bottom 40 percent of the income and wealth distributions.

Producing estimates of changes in shares for groups further down in the distribution is of course easier said than done, especially in the case of estimates based on tax data, given that there are a significant number of households that do not file tax returns and for which income would need to be estimated in some other way in order to calculate all the relevant income shares. Nonetheless, this seems to me to be a worthy objective for future research by this team of authors.

\section{REFERENCES FOR THE ABRAHAM COMMENT}

Groves, Robert M., Floyd J. Fowler Jr., Mick P. Couper, James M. Lepkowski, Eleanor Singer, and Roger Tourangeau. 2009. Survey Methodology, 2nd Edition. New York: Wiley. 
Kopczuk, Wojciech, Emmanuel Saez, and Jae Song. 2010. "Earnings Inequality and Mobility in the United States: Evidence from Social Security Data since 1937." Quarterly Journal of Economics 125, no. 1: 91-128.

Saez, Emmanuel, and Gabriel Zucman. 2016. "Wealth Inequality in the United States since 1913: Evidence from Capitalized Income Tax Data." Quarterly Journal of Economics 131, no. 2: 519-78.

Steuerle, C. Eugene, and Caleb Quakenbush. 2015. "Social Security and Medicare Lifetime Benefits and Taxes, 2015 Update." Research Report. Washington: Urban Institute.

\section{COMMENT BY}

WOJCIECH KOPCZUK Jesse Bricker, Alice Henriques, Jacob Krimmel, and John Sabelhaus have produced very careful estimates of the magnitude and trends (from 1989 to 2013) in top wealth and income shares in the United States, relying on data from the Survey of Consumer Finances (SCF). This is of course not a new question, and the existing estimates of the top 1 percent share and the like have been highly influential, both in the economic literature and in broader public discussions. This paper adds to the existing evidence by providing high-quality estimates and by reconciling discrepancies between different methods. The authors' key contribution is their estimation of the top wealth shares, a topic on which there has been recent controversy.

Before delving into the details of the paper, it is useful to comment on the broader question of why one might be interested in wealth inequality, and in the top shares in particular. The paper's opening paragraph signals one reason: There is much popular interest in this topic. I take as given that we may be interested in inequality - but why in wealth? Wealth is a much more complicated outcome than income. Income itself does not measure the inequality of well-being or opportunities, and it comingles them with decisions about skill acquisition, occupational choice, hours of work, effort, saving, and portfolio choice. Focusing on wealth shares has the same problems, and adds some. It is inherently linked to the life-cycle dynamics of wealth accumulation - it is an outcome of the income, transfer, spending, and investment decisions that individuals make up to a particular point in time when they happen to be observed. In the natural economic approach, wealth reflects potential consumption (including that done in the form of transfers to others). Correspondingly, it is related to lifetime resourcesand it does have advantages over permanent income, in that it responds to intergenerational transfers. However, if this is the objective of analyzing wealth inequality, then one should make clear how lifetime resources and 
wealth are related, and should at least account for age distribution—having the same amount of wealth means something very different at age 20 than at 65. Alternatively, one may be interested in the distribution of wealth itself rather than in learning from it about the distribution of consumption opportunities. The economic rationale for separating wealth from its consumption value is more speculative, but one can certainly consider the notions of political and personal power, and of control or status, that are tied to it. Arguably, the higher one goes in the distribution, the more important these issues become, providing some cover for focusing on the top wealth shares as they are, without a more carefully specified conceptual framework. This is not a complaint about this paper-measurement is important—but just a discussant's reminder that there is a considerable distance between what we can measure and the interpretation of what wealth inequality represents.

This paper provides estimates for both income and wealth, but its findings about wealth stand out as its key contribution. This is because estimates of the top wealth shares are much less settled than those of the top income shares, and there is substantial controversy about how they have evolved in recent years. ${ }^{1}$ The paper provides estimates using the SCF, and it offers evidence that enables us to understand the sources of the differences between these estimates and the most prominent recent alternative: the capitalization approach offered by Emmanuel Saez and Gabriel Zucman (2016). The share of wealth of the top 0.1 percent, as estimated in the paper by Bricker and his colleagues, grew between 1989 to 2013 by about 4 percentage points - from a bit under 11 percent to close to 15 percent of aggregate wealth. In contrast, the estimated share of wealth of the same group, as analyzed by Saez and Zucman (2016), doubled from the similar level in 1989 to more than 20 percent in 2013. Both methods show that wealth concentration has increased, but the difference in trends is massive. And the temporal dynamics are also different; using the SCF approach, the top 0.1 percent share fluctuated somewhat but did not change much between 1995 and 2010, so the increase over the whole period is accounted for by changes between 1989 and 1995 and since 2010. In contrast, the capitalization approach shows relentless growth, with just a short break in about 2000.

With such a large difference in results, one would expect there to be a smoking gun as evidence for what is going on-and there is one here:

1. For an extensive discussion, see Kopczuk (2015). 
Looking at the composition of assets of the top groups, the bulk of the discrepancy is due to the amount of fixed-income assets that both approaches yield. Both Saez and Zucman (2016) and I (Kopczuk 2015) have noted this discrepancy before, and this paper makes it clear that this is the mechanical source of the differences. How does it come about?

First, let us start with a potential problem on the SCF side. There is a discrepancy between capital income in the data from the Internal Revenue Service on which Saez and Zucman (2016) rely and what is observed in the SCF data. This could potentially mean that the SCF is not accurately capturing the very top of the distribution. This is certainly true in a narrow and obvious sense; the SCF explicitly excludes those individuals on the Forbes 400 list (to preserve confidentiality), but this particular issue is explicitly dealt with in wealth estimates by adding the estimated wealth of this group to the top shares. ${ }^{2}$ There is an extensive and very informative discussion in the paper about the approach to and quality of sampling in the SCF that compares presurvey income tax information for respondents and nonrespondents. This discussion indicates that the role of the sampling bias is limited, though it cannot prove it plays no role. In principle, it is still possible that even though respondents and nonrespondents are similar in prior years, their income trajectories could potentially diverge in the survey year (and perhaps be related to the reason for the difference in response behavior). This discussion is also limited to sampling for the 2013 SCF, leaving open the possibility of changes in the quality of the SCF's coverage. However, if by 2013 the survey is of a high quality, then the improved coverage of the top shares should strengthen rather than weaken the observed trend.

The paper's authors also note that the overall level of income of the top groups is consistent between the SCF data and the Internal Revenue Service data on which Saez and Zucman (2016) rely, and only its composition

2. Note, however, that this approach takes at face value the estimates of net worth reported in Forbes publications. There are reasons to be skeptical about precision here; these estimates sometimes mix the wealth of a whole family with an individual's wealth, and they may miss some components of net worth, in particular debt. Raub, Johnson, and Newcomb (2010) compared the Forbes estimates with estate tax reports for individuals who died while on the list and found that reported estates are only about 50 percent of the Forbes numbers. Though some of this may reflect tax avoidance, the magnitudes are substantially larger than existing evidence of the extent of tax avoidance (Kopczuk 2013), suggesting that Forbes is likely to somewhat overestimate the net worth of these individuals. Hence, if anything, I suspect that the approach taken by the Forbes list leads to upward bias in estimated top shares. 
between capital income and other sources (primarily wages) differs. They speculate that the explanation may have to do with varying notions in the tax and survey data of what constitutes labor versus capital income, especially for business owners. I am quite sympathetic to this argument-as any public finance economist working on capital taxation knows, the line between labor and capital is inherently imprecise, and it is certainly possible that tax accounting differs from the common-language way of separating labor from capital. I also find persuasive the argument that the close match of the overall income concentration measures suggests differences in the classification of income rather than bias. Still, at the end of the day, there is a difference in capital income observed in the two sources, and this is clearly an important future research area for improving our understanding of the SCF's concepts and quality of sampling. Also, perhaps more can be done with the existing data to further explain which components of capital income are a problem and how these discrepancies evolved over time.

The alternative explanation for the discrepancy has to do with how capitalization estimates are constructed. In Saez and Zucman's (2016) capitalization approach, observed capital income must be multiplied by a capitalization factor in order to arrive at the underlying level of wealth. Thus, if unobserved asset worth $A$ generates observed return $r A$, one needs to multiply $r A$ by the capitalization factor, $1 / r$, to arrive at the original stock. If realized $r$ were known, this would be an uncontroversial-and trivialprocedure. However, $r$ varies over time, it varies on average across asset classes, and it varies across individual portfolios within an asset class. In a nutshell, Saez and Zucman's (2016) approach is to use aggregate information about flows and stocks by asset classes to construct average capitalization factors, while assuming that they do not vary across income distributions and providing a battery of approaches and outside data to test sensitivity. This procedure still allows for differences in rates of return across income groups, because their portfolio compositions might differ, but this can only be due to differences in portfolio composition across very broad asset classes, which include fixed income, equities, business assets, and housing — categories that match the limited level of detail observed in data on income tax returns.

For all this approach's reliance on microeconomic data, the capitalization factor for a particular asset class is a single number for a particular year, which is constructed on the basis of aggregate data. Any bias in this factor skews the estimated value of the whole asset class. Any bias in its trend generates a trend in the estimated value of the underlying asset. In an environment with a low rate of return, a seemingly small bias in the 
estimated rate of return has large consequences. The capitalization factor for taxable interest income used by Saez and Zucman (2016) for 2009 is 96.6, which corresponds to the estimated rate of return of 1.04 percent for the asset class that it reflects in the economy as a whole. Hypothetically, imagine that we are underestimating the true rate of return by 1 percentage point. In this case, the true capitalization factor would be 50 (or, if it were instead an upward bias, it could be $2,500 \ldots$. ), so the assumed 96.6 capitalization factor would erroneously double the amount of wealth estimated in this particular asset category! In an environment with a higher rate of return, however, the implications of mismeasurement will be more benign. In the 1990s, the capitalization factor for taxable interest income was about 25 . In that case, increasing the corresponding rate of return by 1 percentage point, from 0.04 to 0.05 , would modify the capitalization factor to 20-still a bias, to be sure, but the value of the assets would be overestimated by 25 percent rather than 100 percent.

Moving beyond hypothetical situations, the paper's figure 9 shows that directly observed rates of return on some fixed-income assets (Treasuries, bonds) are higher than those implied by observed interest income on individual income tax returns, as analyzed by Saez and Zucman (2016), so that relying on them would translate into large differences (by a factor of 2 or more, by the end of the period) in capitalization factors. The paper's figure 10 then shows that reducing the capitalization factor for fixed-income assets brings the estimates of the SCF and Saez and Zucman (2016) much closer to each other, especially in the 2000s, when they track each other fairly closely.

The paper's authors suggest that the overestimation of the capitalization factor is the reason for the discrepancy in fixed-income estimates that constitutes the bulk of the difference. I have also suggested so in the past (Kopczuk 2015), and thus-not surprisingly-I concur. The key series for me are those capitalization factors that rely on the linked estate and (pre-death) income tax data; this approach constructs the rate of return that is specific to a high-net-worth population and, in particular, it reflects a wealthy-specific portfolio composition within asset classes. One can still worry about the quality of information for the estate tax versus the income tax, the timing of when income and wealth are observed, and the representativeness of those who died for the whole wealthy group. However, the fact that it moves closely in sync with the Treasury rate and its growing discrepancy with the series assumed by Saez and Zucman (2016) over the 2000s strongly suggest the existence of a trending bias in their capitalization factor. If the capitalization factor based on the estate-income rate of 
return was the approach used in the baseline figures of Saez and Zucman (2016) (rather than that reported in their figure B27b, on page 79 of their 385-page-long online appendix ${ }^{3}$ ), we would be left with an understanding of the remaining discrepancies in figure 10 rather than of the major differences in trends shown in figure 1.

Having said this, the remaining and interesting question is why the interest income observed on income tax returns would imply too low a rate of return. Let us assume that there are no problems with measuring the underlying aggregate stock of fixed-income assets. There are two main possibilities. One is that some interest income is not reported or that some fixed-income assets generate no interest income (my checking account!). The other possibility (which is closely linked) is that fixed-income assets are still a broad category that, in particular, includes checking accounts, savings accounts, certificates of deposit, and bonds. In practice, these different types of investments correspond to different rates of return, but Saez and Zucman's (2016) capitalization factor is based on the average rate of return for the whole class. The much lower implied capitalization factor, which is based on an income-estate link that is not far from the Treasury rate, suggests that the portfolios of the wealthy are tilted toward higheryield assets (for example, bonds) relative to the general public's lowinterest deposits. This would always result in bias; but in a world where the general public earns 3 percent and the top of the distribution earns 5 percent, this bias is much smaller than in a world of 0 percent versus 2 percent earnings. If, for simplicity, each group had half the aggregate assets, we would be back to my original example, with average rates of 4 percent and 1 percent and a 1 percentage point difference between the average rate of return and the one that should be used for the wealthy population.

I am not aware of any outside evidence (other than the capitalization method) that would indicate that between 2000 and 2012, the top 0.1 percent did indeed rebalance their portfolios to increase their holdings of fixed-income assets from 21 to 43 percent of their net worth, as implied by the approach taken by Saez and Zucman (2016, table B5b). This finding is driven by declining fixed income, multiplied by strongly increasing capitalization factors. Given the issues with constructing the capitalization factors, I find the evidence in this paper that indicates no such rebalancing in the SCF much more plausible.

3. The online appendix is found at http://eml.berkeley.edu/ saez/SaezZucman2016QJE Appendix.pdf. 
In conclusion, this very valuable paper provides timely and careful estimates of the top wealth shares and makes a persuasive argument for the source of the discrepancy between these results and those of Saez and Zucman (2016). This is not a mortal blow to the capitalization method; nor is it intended to be one. The two methods are certainly complementary, and one way of describing the discrepancy's source is that it is due to a particular implementation of the capitalization method rather than the method itself. Adjusting capitalization factors to match the portfolios of the rich is certainly a feasible task. However, the paper does highlight how the capitalization approach is very sensitive to hard-to-estimate capitalization parameters and how the assumption of the constant rate of return across income groups for broad asset classes is potentially problematic. This approach is also heavily based on tax reporting, with all its associated conceptual problems. Hence, I view it as a complement to approaches that are based on observing wealth directly (such as surveys, the administrative data on wealth available in some countries, and estate tax data) rather than the preferred alternative. In the United States, the SCF remains the prime source of information for understanding wealth distribution.

\section{REFERENCES FOR THE KOPCZUK COMMENT}

Kopczuk, Wojciech. 2013. "Taxation of Intergenerational Transfers and Wealth." In Handbook of Public Economics, Volume 5, edited by Alan J. Auerbach, Raj Chetty, Martin Feldstein, and Emmanuel Saez. Amsterdam: North-Holland.

- 2015. "What Do We Know about the Evolution of Top Wealth Shares in the United States?" Journal of Economic Perspectives 29, no. 1: 47-66.

Raub, Brian, Barry Johnson, and Joseph Newcomb. 2010. "A Comparison of Wealth Estimates for America's Wealthiest Decedents Using Tax Data and Data from the Forbes 400." In Proceedings of the 103rd Annual Conference on Taxation. Washington: National Tax Association.

Saez, Emmanuel, and Gabriel Zucman. 2016. "Wealth Inequality in the United States since 1913: Evidence from Capitalized Income Tax Data." Quarterly Journal of Economics 131, no. 2: 519-78.

GENERAL DISCUSSION Moderator James Stock began by posing two simple questions intended to help frame the discussion to come. First: What, from an economist's perspective, do we mean by income, and is that something that is available for current consumption? And second: What do we mean by wealth? Noneconomists tend to conflate the two terms, so 
he thought that a really clear statement about the definitions of the ultimate economic objects was a good place to start.

Justin Wolfers suggested that when the general public asks about what the level of wealth and inequality is, economists generally have two choices: The first is simply to measure it, and the second is to patiently explain to the general public that wealth is a less useful concept than casual intuitions would suggest. He suggested that the next time someone asks him about the level of wealth inequality, he may just refuse to answer the question. He added that if economists' role in this debate is to educate the public, what is important is actually understanding the concept that the public is after, which he argued is not actually the economic concept of wealth.

Martin Feldstein made three comments following his observation that although income distribution research is a very interesting subject, one real obstacle is that the interesting parts of the income distribution-the very top and the very bottom-are where the data are most uncertain. He first noted that one thing that was not included in the authors' tabulations was Social Security wealth, despite the fact that for most people, it is the thing that they count on for retirement income for themselves and for their survivors. According to Feldstein, the Social Security trustees estimate that current Social Security wealth is about $\$ 59$ trillion. Household net worth, by comparison, is about $\$ 80$ trillion. Additionally, Medicare and Medicaid wealth is estimated to be roughly $\$ 50$ trillion. Between Social Security wealth, Medicare wealth, and Medicaid wealth, the total far exceeds official household net worth. He wondered if the authors had an explanation for these seemingly large omissions.

Second, Feldstein was interested in wealth's relation to political influence and power, and what that might mean for high-income people. He suspected that, in reality, one probably does not garner a lot of political influence and power from being in the 99th, or even the 99.9th, percentile of the wealth distribution, where annual incomes are only about $\$ 500,000$ and \$1.6 million, respectively. Last, Feldstein commented on measuring incomes over time. Data from Thomas Piketty show that a big shift in inequality at the top income percentiles started to happen in the 1980s, and Feldstein believed that a lot of that was driven by tax changes. For example, the top marginal tax rate on investment income declined from 70 percent in 1980 to 50 percent, and eventually to 28 percent, meaning the net-of-tax share rose from 30 percent to 72 percent. Not surprisingly, people chose to recognize more income on their tax returns, and that is 
where one begins to see all the data for the very top percentiles. Even more important, he argued, were the major changes in tax rules brought about by the Tax Reform Act of 1986. The reforms induced individuals who had a separate small corporation in their own name to shift that income from the corporation into their regular income tax returns, which led to a big increase in reported personal incomes. He therefore concluded that it could be misleading or inappropriate to compare post-1986 personal incomes with pre-1986 data.

Matthew Shapiro protested against obsessing over the shares of wealth. More important, he argued, was what levels go with the values of these shares, and how they have evolved over time. It is very different if wealth has doubled and all the wealth has gone to some group versus wealth being stagnant and one group getting more. The reality is that the situation is probably something in between. Likewise, Shapiro added that one should probably also care about the composition of the changes, which he believed was buried in the authors' numbers. He thought it would be nice if the paper included some of the level information and some ways one might think about its shifts. While the shares are interesting, so are the levels and the sources of the changes in levels.

Scott Winship believed that the paper lent support to the usefulness of the Congressional Budget Office's income concentration data. He wondered if the authors had any plans to look into measuring income from gains on an accrual basis rather than when they are realized, which Jeff Larrimore, Richard Burkhauser, and others have shown does make a big difference. Realized gains are lumpy, and if one could produce estimates that distribute those gains in some sense over the period in which assets are held, that could make a noticeable difference in the estimates, especially for the levels.

Janice Eberly was struck by the observation that so much of the divergence in measurement was driven by the fixed-income sector. She argued that although discussant Wojciech Kopczuk did a nice job of pointing out in his presentation how sensitive those valuations are to low levels of interest rates, it did not absolve anyone from trying to figure out what is going on in the U.S. Financial Accounts. The measure that comes out of the Financial Accounts might be implausible, in that it is out of line with other measures, but it is still important to know why it is implausible. Saying that the results are sensitive indicates that one should be worried about the effect of small errors, but it does not absolve anyone from still trying to get the best point estimate. Eberly argued that simply ignoring the Financial Accounts might 
not be the right way to go, and wondered if the authors or others in the room knew why the Financial Accounts were not only off but also increasingly off, and how this is related to the measurement of fixed-income assets. She added that the U.S. Treasury Department has put a lot of effort into getting better disclosure and better information on international accounts through the Foreign Account Tax Compliance Act, and wondered if those efforts might be driving some of the divergence.

Alan Blinder wondered if there was more that could be said about the underreporting of closely held business assets, which he believed to be quite substantial, and whether it had increased or decreased. William Brainard wondered how much the likelihood that some individuals in the very-high-income distributions move their money to places that minimize their estate tax obligation biases the authors' estimates. Another speaker noted that a lot of the wealth held by the very wealthy usually takes the form of things that are objectively very hard to value; they are not things that have a daily market value, and one can only know the value once they are sold. She wondered if it was important to acknowledge that imprecision, and how much of an issue it might be for the estimates.

In response to Brainard's question about estate tax avoidance, Kopczuk noted that it is definitely a big issue, and that it may show up in various estimates. He cited a paper published in 1977 about the very issue as evidence that estate tax avoidance is not a new concern. ${ }^{1}$ In fact, the incentives were stronger in the past than they are now because the tax rates were higher. He found it implausible that there has been a huge trend in tax avoidance that would be severely skewing the data. He agreed with Feldstein that the tax reform of the 1980s had a substantial effect on income observable on personal tax returns, skewing measurement of the distribution of income and, possibly, of wealth. He cited evidence from Norway showing that such reporting effects are quantitatively important.

Discussant Katharine Abraham agreed with Eberly that it is certainly worth looking more carefully at the Financial Accounts to understand what is going on with them, though she warned that the problems may not lie there. Rather, there may be problems related to the reporting of interest income. She explained that in an environment of very low interest rates, there are a lot of people who have significant assets with very low interest earnings, so low that they are not reporting them on their tax returns.

1. George Cooper, "A Voluntary Tax? New Perspectives on Sophisticated Estate Tax Avoidance," Columbia Law Review 77, no. 2 (1977): 161-247 (reprinted in 1979 by the Brookings Institution Press). 
She pointed to some interesting calculations done by the authors that suggest that that could account for a big chunk of the growth in the observed concentration of fixed-asset wealth at the top of the distribution because the total unreported interest incomes of many people at the bottom of the distribution who hold small accounts may add up to a substantial amount.

In response to Stock's opening comment about the concepts and what exactly the present paper is trying to measure, John Sabelhaus noted that measuring wealth is essentially measuring potential consumption. Measuring income, on the other hand, has more to do with behavior, and asks the question: How much of that potential consumption are people actually consuming? He agreed with Wolfers that it is important to communicate exactly what economists are measuring when they talk about wealth, and that the concept of wealth may not actually be what people think it is.

On the questions of measurement and capitalization factors, Sabelhaus noted that the authors had done a lot of digging into what could be going wrong with the measurement of not-for-profit holdings in the Financial Accounts, and the measurement of taxable interest income on individual tax returns, much of which he noted was slipping over into tax-preferred retirement accounts. He also added that low interest rates exacerbate the measurement problems.

On the question of the underreporting of small businesses' assets, Sabelhaus stated that they are really tricky to value, but added that the authors did not see that as a particular problem, and that he believed they did a good job on that front. 